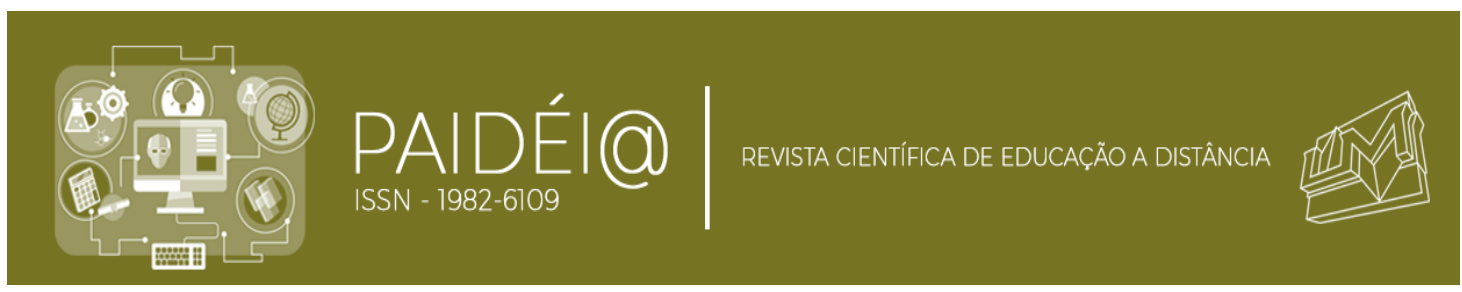

\title{
FATORES DE ENGAJAMENTO DOS LICENCIANDOS EM PEDAGOGIA NA PARTICIPAÇÃO DE LIVES EM UM CURSO A DISTÂNCIA
}

\author{
Fabiana Santos Cotrim ${ }^{1}$ \\ Lilian Patrícia Lima ${ }^{2}$ \\ Mariana dos Santos Cezar ${ }^{3}$ \\ Sandra Menezes ${ }^{4}$ \\ Glauce Barbosa Verão ${ }^{5}$
}

DOI: $10.29327 / 3860.13 .23-4$

\begin{abstract}
Resumo
O presente trabalho buscou investigar os fatores associados ao engajamento dos licenciandos de pedagogia na participação de Lives, em disciplinas que discutem fundamentos e práticas no ensino de Ciências e Matemática. Nesse sentido, temos como questão diretriz desta investigação: Que fatores estão associados ao engajamento dos licenciandos de pedagogia na comunicação e interação em Lives? Para o desenvolvimento deste estudo, optamos pelos pressupostos metodológicos da pesquisa qualitativa, cuja coleta de dados foi realizada por meio de questionários online aplicados aos licenciandos. A fundamentação teórica e a análise dos dados tiveram como embasamento as dimensões de engajamento no Ensino Superior e os diferentes tipos de interações que ocorrem na EaD. Os resultados mostraram que os estudantes buscam por meio de suas participações nas Lives uma formação mais direcionada ao desenvolvimento de competências, contemplando a aquisição de conhecimentos, de habilidades e de atitudes, bem como refletir coletivamente sobre a prática docente. Por outro lado, a pouca indicação de fatores associados a discussões sobre a prática docente, especificamente sobre aspectos que motivam a participação dos estudantes nas Lives, revelou que possivelmente este ambiente ainda seja um espaço pouco direcionado à formação profissional em âmbito mais prático.
\end{abstract}

Palavras-chave: Educação a distância. Lives. Engajamento. Interações.

\footnotetext{
${ }^{1}$ Mestra em Matemática pela Universidade Federal de São Carlos (UFSCAR). Doutoranda em Ensino de Ciências e Matemática pela Universidade Estadual de Campinas (UNICAMP). Professora da UFSCAR Campus Lagoa do Sino.

${ }^{2}$ Mestra em Ensino de Ciências pela Universidade de São Paulo (USP). Doutoranda em Ensino de Ciências e Matemática pela Universidade Estadual de Campinas (UNICAMP).

${ }^{3}$ Mestra em Educação em Ciências e Matemática pelo Instituto Federal do Espírito Santo (IFES). Doutoranda em Ensino de Ciências e Matemática pela Universidade Estadual de Campinas (UNICAMP). Professora do Ifes - Campus Nova Venécia.

${ }^{4}$ Mestra em Modelagem Computacional pela Universidade Estadual do Rio de Janeiro (UERJ). Doutoranda em Ensino de Ciências e Matemática pela Universidade Estadual de Campinas (UNICAMP).

${ }^{5}$ Doutora em Matemática pela Universidade de São Paulo (USP). Docente na Universidade Virtual do Estado de São Paulo (Univesp) e na Universidade São Judas.
} 


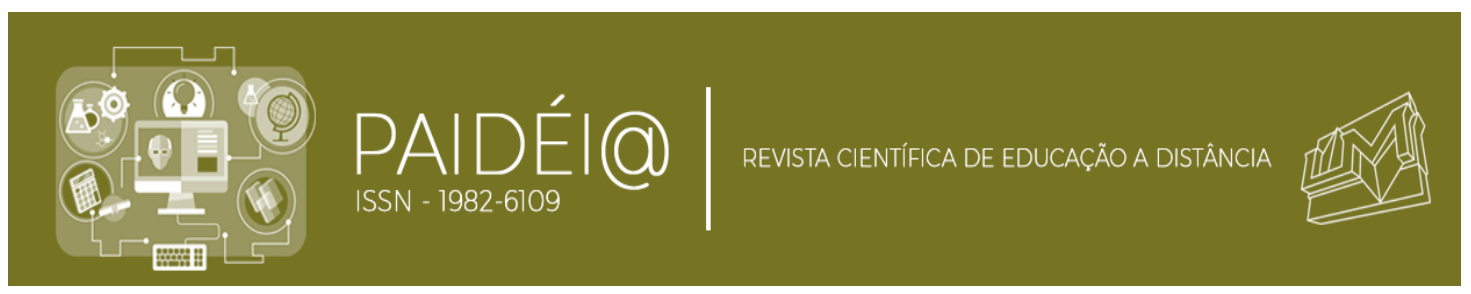

\section{Abstract}

The present study sought to investigate the factors associated with the engagement of pedagogy undergraduates in the participation of Lives, in disciplines that discuss fundamentals and practices in the teaching of Science and Mathematics. In this sense, we have as a guiding question of this research: What factors are associated with the engagement of pedagogy undergraduates in communication and interaction in Lives? For the development of this study, we opted for the methodological assumptions of qualitative research, whose data collection was carried out through online questionnaires applied to undergraduate students. The theoretical basis and data analysis were based on the dimensions of engagement in Higher Education and the different types of interactions that occur in distance education. The results showed that students seek through their participation in Lives a training more directed to the development of skills, including the acquisition of knowledge, skills and attitudes, as well as reflecting collectively on the teaching practice. On the other hand, the low indication of factors associated with discussions on teaching practice, specifically on aspects that motivate students' participation in Lives, revealed that possibly this environment is still a space little directed to professional training in a more practical scope.

Palavras-chave: Distance education. Lives. Engagement. Interactions.

\section{INTRODUÇÃO}

A Educação a Distância (EaD) e o ensino presencial se diferenciam por diversos fatores, mas os meios de interação e a qualidade desses meios, são os principais. $\mathrm{Na} \mathrm{EaD}$, o ensino é mediado por meio do uso de Tecnologias, que dispõem de ferramentas que possibilitam o processo interativo e dialógico na modalidade. Nesse universo, diversas são as ferramentas tecnológicas que podem ser utilizadas no Ambiente Virtual de Aprendizagem (AVA), e por meio delas é possível dialogar sobre conteúdos e práticas, refletir e trocar experiências, esclarecer dúvidas, entre outras ações, que possibilitam a construção de conhecimentos e facilitam os processos de ensino e de aprendizagem.

A escolha das ferramentas a serem utilizadas para a comunicação na EaD depende da particularidade de cada curso e Instituição. Para a seleção da tecnologia a ser utilizada é importante considerar o perfil dos estudantes, a proposta metodológica do curso, a missão da Instituição, os objetivos de aprendizagem, entre outros elementos que compõem e estruturam o processo de formação. Além disso, é importante ressaltar que nenhuma tecnologia por si só é o melhor meio para que a mensagem alcance a todos os estudantes, ou seja, é necessário um conjunto de ferramentas tecnológicas para que a comunicação com o estudante seja efetivada com sucesso. 


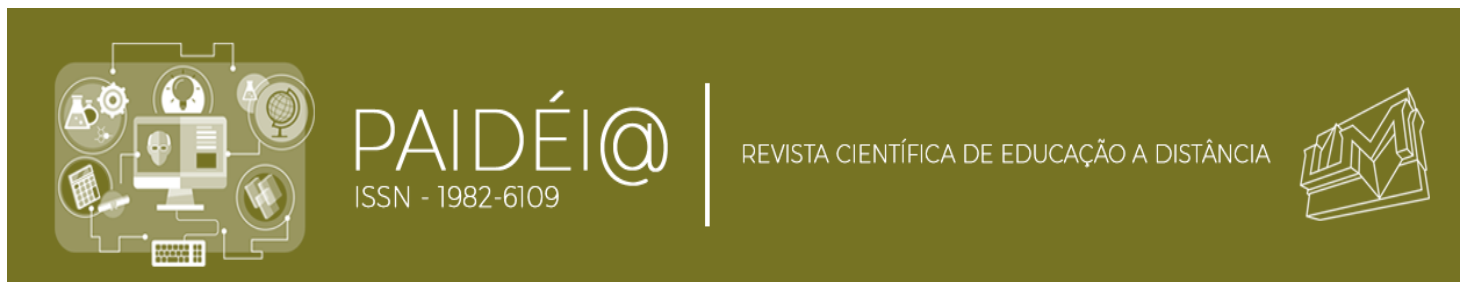

O conjunto de ferramentas tecnológicas pode viabilizar a comunicação com o estudante em momentos assíncronos e síncronos. Os momentos assíncronos são viabilizados por ferramentas que possibilitam ao estudante desenvolver sua aprendizagem com uma maior liberdade, de acordo com o tempo e local disponíveis (MARTINS; JUSTINO; GABRIEL, 2010). Nesses momentos, busca-se o desenvolvimento de uma maior autonomia do educando, o que requer um maior comprometimento dos estudantes. As ferramentas mais comuns são: fórum, e-mail, blog, caixa de mensagens AVA, WhatsApp, entre outras. Os momentos síncronos são viabilizados por ferramentas que possibilitam o contato direto, em tempo real, dos participantes. Esse momento possui como principal característica a interatividade gerada pela presença dos participantes que pode potencializar um clima de comunidade (MARTINS; JUSTINO; GABRIEL, 2010). Assim, ambos devem estar conectados no mesmo momento por meio de algum recurso tecnológico. As ferramentas utilizadas são variadas: webconferências, chats, chamada de vídeo pelo WhatsApp, entre outras.

Das ferramentas que viabilizam à interação nos momentos síncronos, destacamos a webconferência, também denominada Live $e^{6}$. Segundo Martins e Pimentel (2012), a webconferência oferece um ambiente integrado para que estudantes e professores se comuniquem por áudio, vídeo, slides, mensagens de texto, entre outras formas que possibilitam a interação dos participantes. Essa ferramenta é de fácil operacionalização, pois não necessita de equipamentos sofisticados, o que facilita o acesso e a comunicação entre as pessoas.

Nessa perspectiva, "a introdução da webconferência em cursos à distância justificase pela necessidade de se fazer uma transição entre as metodologias de ensino que valorizam o conteúdo para aquelas direcionadas ao diálogo" (MARTINS; QUINTANA; QUINTANA, 2020, p. 183). A relação dialógica estabelecida no momento da webconferência permite uma combinação entre as interações caracterizadas por Hirumi (2013) como humanas e nãohumanas, ou seja, aquelas em que o estudante interage com o professor/facilitador, com outros estudantes ou com outros indivíduos de fora do curso (Interações Humanas), assim

\footnotetext{
${ }^{6} \mathrm{O}$ termo Live é de uso comum dos estudantes, facilitadores, professores e supervisores da Universidade Virtual do Estado de São Paulo. Nessa Instituição, usa-se Live sempre que se pretende realizar uma sessão ou aula com os estudantes ou servidores.
} 


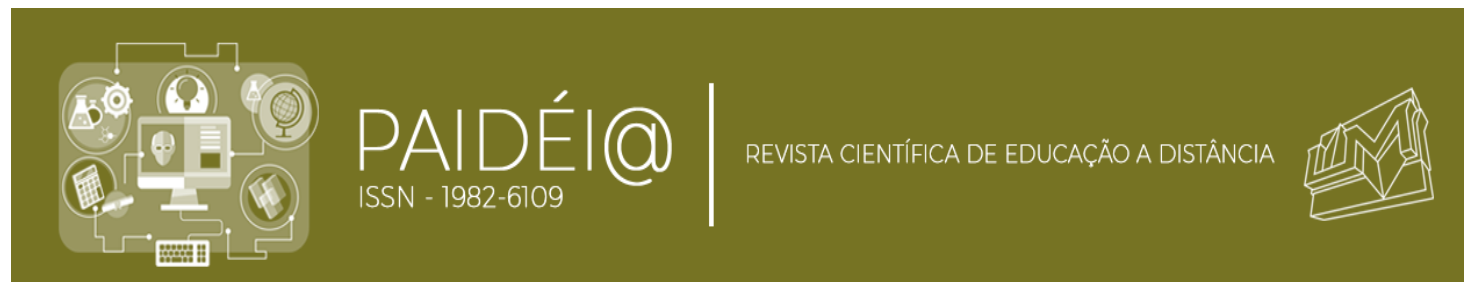

como, aquelas em que ele interage com o conteúdo, com ferramentas e com diferentes ambientes (Interações Não-Humanas).

Considerando a importância dos momentos síncronos para os processos de ensino e de aprendizagem que se desenvolvem na Educação a Distância, em especial, por meio da webconferência, objetivamos nesse trabalho: identificar e analisar fatores associados ao engajamento dos licenciandos em pedagogia, na comunicação e interação em Lives, de acordo com os diferentes tipos de interação que ocorrem no âmbito EaD e os possíveis desdobramentos destas interações para a formação docente.

Tal perspectiva é fruto da experiência que as pesquisadoras desse trabalho tiveram enquanto facilitadoras das disciplinas Fundamentos e práticas no ensino de Ciências da Natureza (SCN001) e Fundamentos e práticas no ensino de Matemática (SEN001), do curso de Licenciatura em Pedagogia da Universidade Virtual do Estado de São Paulo (Univesp). Por atuarem como mediadoras do processo dialógico nas Lives, observaram que alguns estudantes participavam mais ativamente do processo do que outros. Diante disso, se propuseram a investigar os fatores associados ao engajamento dos estudantes nas Lives, o que deu origem ao seguinte problema de pesquisa: Que fatores estão associados ao engajamento dos licenciamentos em pedagogia na comunicação e interação em Lives?

Frente a isso, o presente artigo apresenta os caminhos percorridos para a realização desta pesquisa, bem como os fundamentos teóricos que embasaram a temática, e os resultados obtidos.

\section{A FORMAÇÃO DE PROFESSORES E A EDUCAÇÃO A DISTÂNCIA}

A formação de professores se caracteriza como um fator estratégico primordial na qualidade da educação, pois o papel desempenhado pelo professor na mediação entre os processos de ensino e de aprendizagem é um dos fatores que mais impactam na aprendizagem dos estudantes (HEDGES, 2004). Neste sentido, cursos de licenciatura devem ser orientados para a formação de profissionais qualificados visando o exercício de uma função docente que tenha como principal finalidade o desenvolvimento do educando, tal como é assegurado no Art. 22 da Lei de Diretrizes e Bases da Educação Nacional (LDB) $n^{\circ}$ 9.394/96: “A Educação Básica tem por finalidade desenvolver o educando, assegurar-lhe formação comum indispensável para o exercício da cidadania e fornecer-lhe meios para progredir no trabalho e em estudos posteriores" (BRASIL, 1996, Art. 22). 


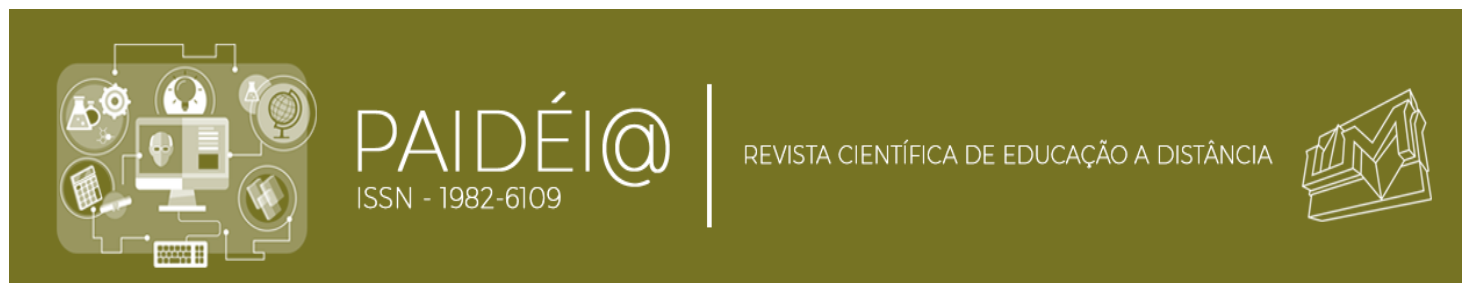

Nas Diretrizes Curriculares Nacionais (DCN) para a formação inicial de professores na Educação Básica recentemente aprovadas (BRASIL, 2019), observa-se ênfase para uma formação mais articulada com a prática profissional que os professores irão exercer, e assim, se destaca uma formação para o desenvolvimento de competências, contemplando a aquisição, não só de conhecimentos, mas também de habilidades e de atitudes.

É também a LDB (BRASIL, 1996) que impulsiona no Brasil a formação de professores na modalidade educativa, pois na época além de regulamentar e se comprometer com o fomento da Educação a Distância, esta lei estabeleceu a formação em nível superior para o exercício do magistério na Educação Básica e neste sentido, se indicava favorável à parceria entre $\mathrm{EaD}$ e formação de professores para suprir a falta desses profissionais no contexto educacional. Desde então, muitos são os estudos e debates acerca desta formação, isso porque, a formação no contexto $\mathrm{EaD}$ possui peculiaridades a qual não cabe uma simples transposição do que é feito na educação tradicional e presencial (MILL, 2013).

Diversos autores discutem que o principal desafio desta modalidade é criar condições de ensino que favoreçam processos de construção de conhecimento, em detrimento de um ambiente exclusivamente associado a transmissão de informação (VALENTE, 2010). No contexto da formação inicial de professores, acrescenta-se que além da construção de conhecimentos, este desafio também inclui o desenvolvimento de habilidades e atitudes que promovam as competências do perfil profissional.

\section{AS INTERAÇÕES E COMUNICAÇÕES NO AMBIENTE EAD}

\subsection{As Interações na EaD}

Uma vez que os sujeitos da $\mathrm{EaD}$ não ocupam os mesmos espaços físicos, são as tecnologias digitais de informação e comunicação (TDICs) que mediam as interações e comunicações neste ambiente. Oliveira e Lima (2013, p. 61) destacam que "a aprendizagem na educação on-line é baseada na qualidade das interações e comunicações que efetivamente ocorrem neste contexto", nesse sentido, a distância não é só uma questão de distância geográfica, mas também um fenômeno pedagógico, com amplo potencial (RIBEIRO, 2019).

Com o constante desenvolvimento das TDICs e, consequentemente, novas formas de interagir na $\mathrm{EaD}$, a questão da interação é um tema amplamente debatido e investigado por especialistas da área de Educação a Distância, principalmente com o objetivo de aprimorar 


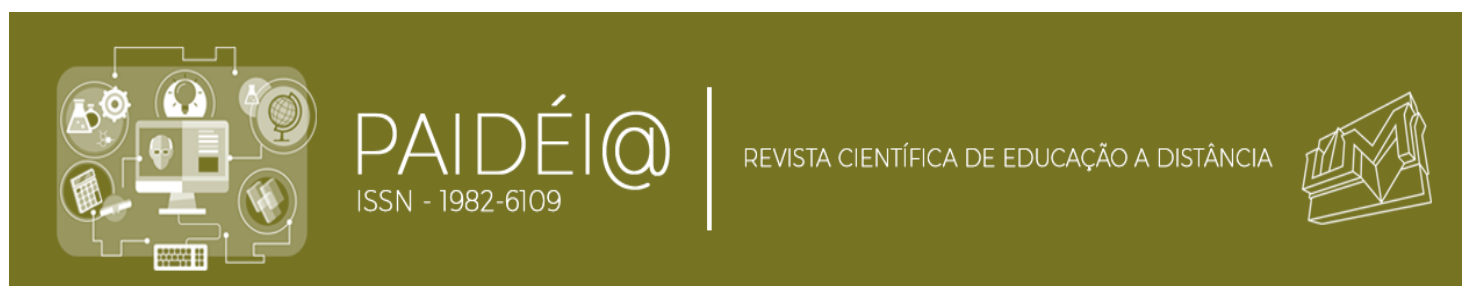

as experiências de ensino e aprendizagem nesta modalidade. Neste sentido, Hirumi (2013), por exemplo, postula um modelo de interação que pressupõe que a aprendizagem na EaD ocorre em três níveis de interação: as Interações do Nivel I, as Interações do Nível II, As Interações do Nível III, conforme destaca-se na figura 1, abaixo:

Figura 1 - Níveis de Interações

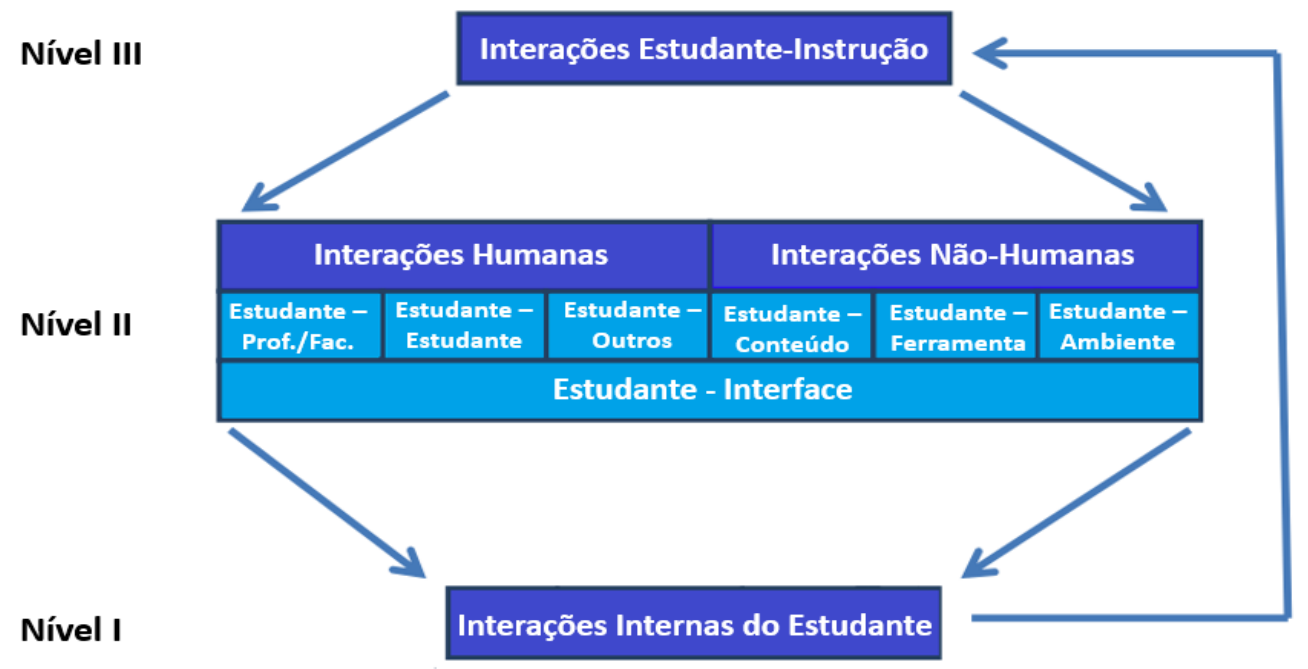

Fonte: Adaptado e traduzido da versão original de Hirumi (2013).

Essas interações foram concebidas por meio de um alinhamento entre as teorias da aprendizagem, estratégias instrucionais e planejamento de interações. Assim, descrevemos cada uma dessas interações:

As Interações do Nivel I, estão associadas aos processos mentais que resultam na aprendizagem do estudante, aos processos metacognitivos que ajudam o estudante a monitorar e regular o próprio aprendizado, ou seja, às interações internas do indivíduo.

As Interações do Nível II, estão relacionadas a sete tipos de interações, concebidas pela compreensão de que o estudante na EaD interage tanto com recursos humanos, como não-humanos.

As Interações do Nível III estão relacionadas às estratégias instrucionais adotadas para compor o contexto de aprendizagem virtual, ou seja, envolvem uma organização intencional de eventos para promover a aprendizagem e facilitar o alcance do objetivo. $\mathrm{O}$ Nível III é considerado um metanível, ou seja, ele transcende e reporta os demais, é usado para guiar o designer e o sequenciamento das interações do Nível II, mas também é condicionado ao Nível I, pois o desenho instrucional pode assumir formas distintas, de 


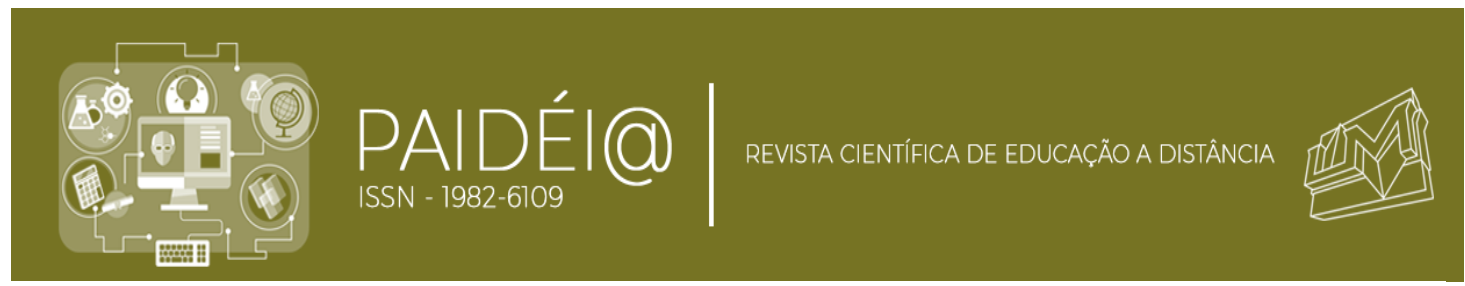

acordo com valores e crenças sobre como e por que as pessoas aprendem - aportados pelas diferentes teorias de aprendizagem.

A partir dessa compreensão, temos como proposta discutir neste estudo, em especial, as Interações do Nível II proposta por Hirumi (2013).

As Interações do Nível II, estão relacionadas a sete tipos de interações, concebidas pela compreensão de que o estudante na EaD interage tanto com recursos humanos, como não-humanos. Os tipos de interação que podem ocorrer são determinados pelo designer instrucional, objeto do Nível III, e influenciam como ocorrerão as interações no Nível I, ou seja, a forma como os estudantes aprenderão.

A primeira destas setes interações retrata Interações Estudante-Interface. A interface é entendida como o recurso digital que possibilita a interação dos estudantes tanto com os recursos humanos, como os recursos não-humanos. Hillman, Willis e Gunawardena (1994) propõem que o grau de proficiência do estudante com um meio, se correlacione, positivamente, com o grau de sucesso dos estudantes na extração de informações desse meio.

Concernente as Interações Humanas, Hirumi (2013) apresenta três formas em que essas podem ocorrer: Interações Estudante-Professor/Facilitador ${ }^{7}$, Interações EstudanteEstudante e Interações Estudante-Outros.

Interações Estudante-Professor/Facilitador podem ser iniciadas pelo estudante ou pelo professor/facilitador. No primeiro caso, o estudante pode interagir com o professor/facilitador para fazer e/ou responder perguntas, esclarecer e confirmar os resultados/objetivos de aprendizagem, explicar condições, enviar tarefas e concluir atividades. O professor/facilitador, por sua vez, pode interagir com o estudante para mediar e facilitar situações de aprendizagem, bem como fornecer feedback oportuno e apropriado.

Interações Estudante-Estudante ajudam grupos e indivíduos a construir conhecimentos e a realizar atividades direcionadas, dentro de um contexto de aprendizagem, em que são compartilhados informações, opiniões e insights. Formas mais envolvidas de interações Estudante-Estudante podem pedir aos estudantes que trabalhem juntos para analisar e interpretar dados, assim como, resolver problemas.

\footnotetext{
${ }^{7}$ Facilitador - participante do curso Lato Sensu de Formação Didático-Pedagógico para Cursos na Modalidade a Distância ofertado pela Universidade Virtual do Estado de São Paulo (UNIVESP), que desenvolvem atividades práticas de mediação pedagógica nos cursos de graduação da mesma instituição.
} 


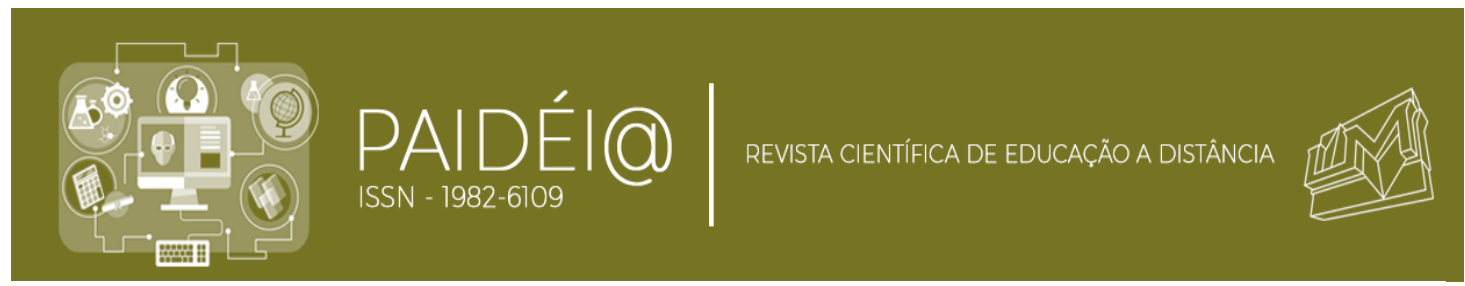

Interações Estudante-Outros abrange todas as interações que um estudante pode ter com pessoas de fora do curso, podendo incluir família, colegas de trabalho, amigos e instituições, ou seja, interações com a cultura, de uma maneira ampla.

Concernente as Interações Não-Humanas, Hirumi (2013) também apresenta três formas em que essas podem ocorrer: Interações Estudante-Conteúdo, Interações EstudanteFerramentas e Interações Estudante-Ambientes.

Interações Estudante-Conteúdo ocorrem a partir da compreensão que o estudante não é um agente passivo e receptor de informação e sim, um sujeito ativo que quando em contato com um conteúdo, o explora, o questiona, estabelece relações, reflete e assume uma posição crítica sobre ele.

Interações Estudante-Ferramentas se tratam de ferramentas que os estudantes mobilizam dentro ou fora do AVA em prol da construção de aprendizagens. Nesse sentido, são incluídas ferramentas de telecomunicações, como por exemplo, correio eletrônico, fóruns de discussão e chats; ferramentas de produtividade, como por exemplo, processadores de texto, planilhas e aplicativos gráficos; ferramentas externas, como por exemplo, um microscópio; ferramentas para produção de conteúdo, como por exemplo, câmeras de vídeo, microfones e outros dispositivos de gravação.

Um outro tipo de interação que não é evidenciada por Hirumi (2013), mas é apresentada por Sutton (2001), é identificada como a Interação Vicária. Esta ocorre quando um estudante, apesar de não estar formalmente em um processo de interação, observa ativamente e absorve as interações envolvendo outro (s) indivíduo (s).

\subsection{Engajamento dos estudantes}

A percepção de sucesso acadêmico das Instituições de Ensino Superior tem se afastado de parâmetros usuais relacionados a objetividade e quantificação, como concluir um curso ou obter um elevado rendimento acadêmico, e têm considerado outros aspectos mais direcionados ao valor que o ensino acrescenta às vidas dos indivíduos e à sociedade (ARAÚJO, 2017). Nesse sentido, em busca de compreender o processo de interação entre instituição e estudantes e as mudanças oriundas desta interação, um dos critérios que tem sido incluído nas pesquisas é o envolvimento, também chamado de engajamento, dos estudantes acerca da sua experiência educativa (ARAÚJO, 2017; ALRASHIDI; PHAN; NGU, 2016). 


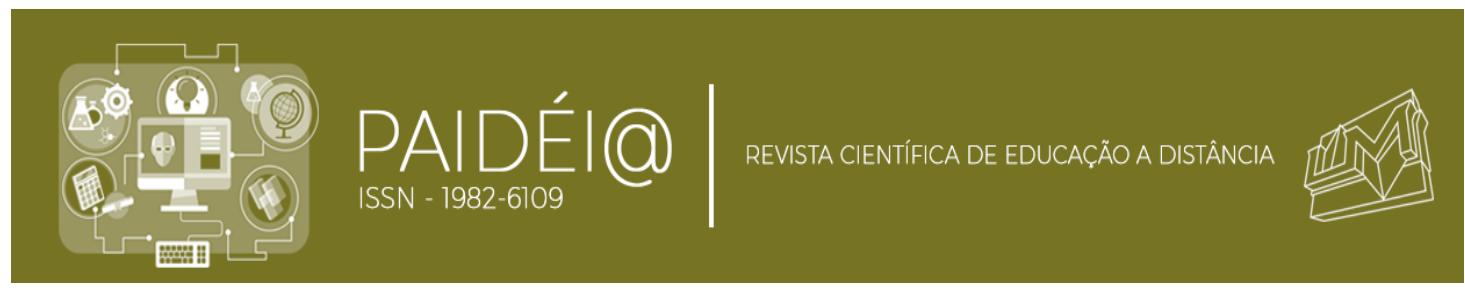

O termo engajamento é um termo complexo, passível de múltiplas significações e de abranger diferentes aspectos, uma vez que pode assumir diferentes tipologias, como por exemplo, a pessoal, moral, social, profissional, identitário, acadêmico e relacional (RIGO; MOREIRA; VITÓRIA, 2018). No campo de pesquisas educacionais, este conceito tem recebido atenção de educadores e pesquisadores da área há algum tempo, sob diferentes perspectivas, adotadas muitas vezes de acordo com a finalidade do estudo. De fato, o estudo sobre engajamento pode estar direcionado a como aumentar a motivação e o envolvimento dos estudantes nas atividades acadêmicas, aumentar os níveis de rendimento dos estudantes ou como inicialmente citado, orientado para a avaliação do sucesso acadêmico de uma instituição.

Mesmo entre diferentes abordagens e conceitualizações, é possível perceber algum consenso entre os pesquisadores: o termo engajamento utilizado nas pesquisas educacionais se trata de um construto multidimensional e que abrange diferentes aspectos, que operados em um conjunto, permitem refletir uma abordagem positiva dos estudantes em relação à aprendizagem. Para a presente investigação, o engajamento do estudante será compreendido sob a ótica da instituição de ensino e, portanto, direcionado a dimensões relacionadas a qualidade e quantidade do esforço e do envolvimento individual do estudante em atividades oportunizadas pela instituição por meio de políticas e estratégias, cujo objetivo seja a aprendizagem dos estudantes (MARTINS; RIBEIRO, 2017).

Nesse contexto, considera-se três dimensões associadas ao engajamento estudantil sob esta ótica: a Dimensão Cognitiva, que está relacionada a como os estudantes se autorregulam e valorizam a sua aprendizagem, bem como a relevância que percebem dos estudos nestas atividades promovidas pela instituição. A Dimensão Comportamental, que está associada a motivação e atitudes direcionadas a participação nestas atividades. E a Dimensão Emocional, que se trata da autoconsciência de sentimentos e percepções dos estudantes sobre diferentes contextos associados à sua experiência educativa (ALRASHIDI; PHAN; NGU, 2016).

Dentre essas três dimensões, conhecer e compreender que fatores em cada uma delas influenciam o engajamento dos estudantes, pode ser um elemento importante na avaliação do propósito institucional e dos seus contextos educativos, assim como, auxiliar no processo de planejamento e na melhoria dos programas e serviços, sob o ponto de vista do estudante. 


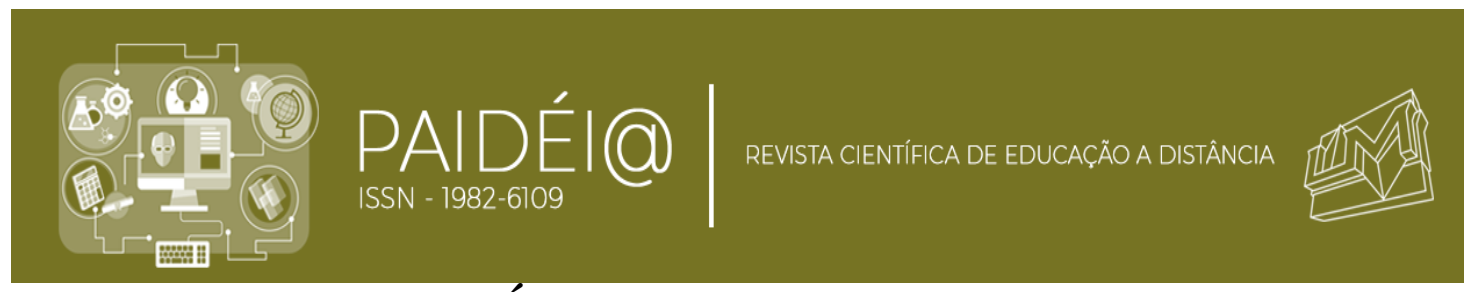

\section{PERCURSO METODOLÓGICO}

A pesquisa em questão se trata de uma pesquisa qualitativa (YIN, 2016), pois centrase na compreensão de aspectos subjetivos relacionados tanto a um fenômeno social, as Lives em $\mathrm{EaD}$, como do comportamento humano decorrentes desse fenômeno, ou seja, o engajamento dos estudantes nessa atividade.

\subsection{Contexto da pesquisa}

Esta pesquisa foi realizada durante a participação das autoras deste artigo, no Programa de Formação Didático-Pedagógica para Cursos na Modalidade a Distância, oferecido pela Universidade Virtual do Estado de São Paulo.

Para tal investigação foi escolhido o curso de Licenciatura em Pedagogia da mesma instituição, que de acordo com seu Projeto Pedagógico do Curso, tem como objetivo formar um profissional capaz de atuar em um mundo em profundas e aceleradas mudanças, através de uma formação técnico-prática e metodológica, fundamentada nos conhecimentos técnicos da Pedagogia e suas áreas correlatas, com ênfase no conhecimento pedagógico e a vivência de experiências relativas ao ensino. A escolha se justificada pelo fato de as autoras atuarem como facilitadoras das disciplinas de Fundamentos e práticas no ensino de Ciências da Natureza (SCN001) e de Fundamentos e práticas no ensino de Matemática (SEN001), que são ofertadas para esse curso.

\subsection{Coleta de Dados}

A coleta de dados foi realizada por meio de um questionário on-line, enviado por email, no período de abril de 2020 a maio de 2020, para estudantes das disciplinas SCN001 e SEN001, contendo sete questões. Com exceção da primeira, que se direcionava a obtenção de informações para a caracterização do perfil dos participantes da pesquisa, as demais questões foram elaboradas com base nas dimensões: comportamental, cognitiva e emocional, recorrentes na literatura sobre engajamento estudantil (ALRASHIDI; PHAN; NGU, 2016).

$\mathrm{Na}$ dimensão comportamental, associada a motivação e atitudes direcionadas a participação das atividades relacionadas, diretamente ou indiretamente ao contexto institucional, foram criadas duas questões: uma buscando obter informações sobre os principais aspectos que motivam a participação em Lives e, a outra, informações sobre as 


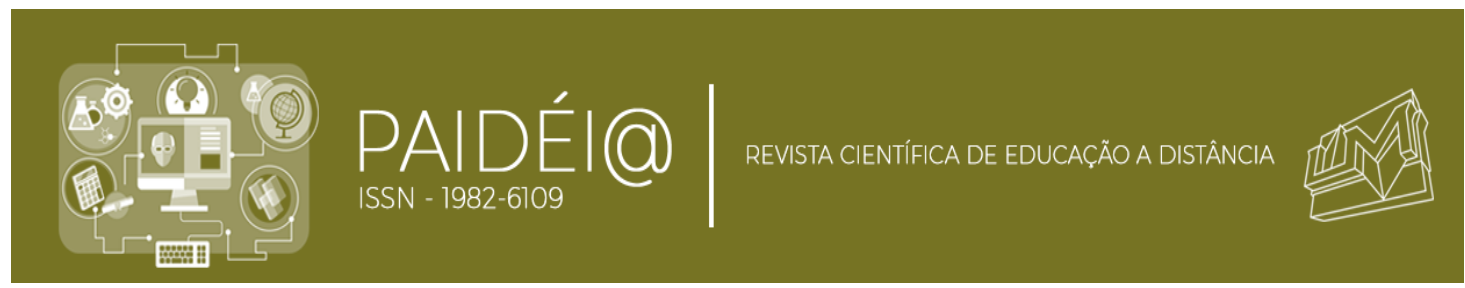

atitudes dos estudantes durantes as Lives. No formato de questões com caixas de seleção, as opções relacionavam-se a diferentes tipos de interações e/ou aspectos da formação docente que podem ocorrer nas Lives.

$\mathrm{Na}$ dimensão cognitiva, relacionada à como os estudantes se autorregulam e valorizam a sua aprendizagem, bem como a relevância que percebem dos estudos em prol da construção do perfil profissional, foram criadas três questões buscando obter informações sobre como as Lives na visão dos estudantes contribuem ou, poderiam contribuir, na formação para o exercício da docência. Uma destas questões, no formato de caixa de seleção, apresentava diferentes fatores que corroboram para a formação docente, pretendendo conhecer qual deles os estudantes associam serem desenvolvidos nas Lives. Nas outras duas questões, no formato de grade de múltipla escolha, direcionava-se o olhar para os objetivos das duas disciplinas SCN001 e SEN001, onde em cada uma das questões, pretendia-se obter informações do quanto na visão destes estudantes as Lives contribuem para alcançar os objetivos da disciplina.

Na dimensão emocional, que se trata da autoconsciência de sentimentos e percepções dos estudantes sobre diferentes contextos associados à sua experiência educativa, criou-se uma questão que, no formato de uma questão aberta, solicitava que o estudante relatasse uma experiência marcante em uma Live das disciplinas SEN001 ou SCN001.

\subsection{Perfil dos participantes que responderam o questionário}

Os sujeitos da pesquisa foram ao todo 257 estudantes do curso de Pedagogia da UNIVESP que faziam a disciplina de Fundamentos e práticas no ensino de Ciências da Natureza (SCN001) e de Fundamentos e práticas no ensino de Matemática (SENO01), sendo que: 240 estudantes cursavam ao mesmo tempo as duas disciplinas; 11 estudantes cursavam apenas a disciplina de Fundamentos e práticas no ensino de Ciências da Natureza e 6 estudantes cursavam apenas a disciplina de Fundamentos e práticas no ensino de Matemática.

\subsection{Análise dos Dados}

A análise dos dados foi realizada de acordo com as cinco fases que Yin (2016), pertinentes a pesquisa qualitativa: Compilar, Decompor, Recompor (e arranjar), Interpretar e Concluir. Relativo à Compilação, a partir das respostas obtidas no questionário, criou-se 


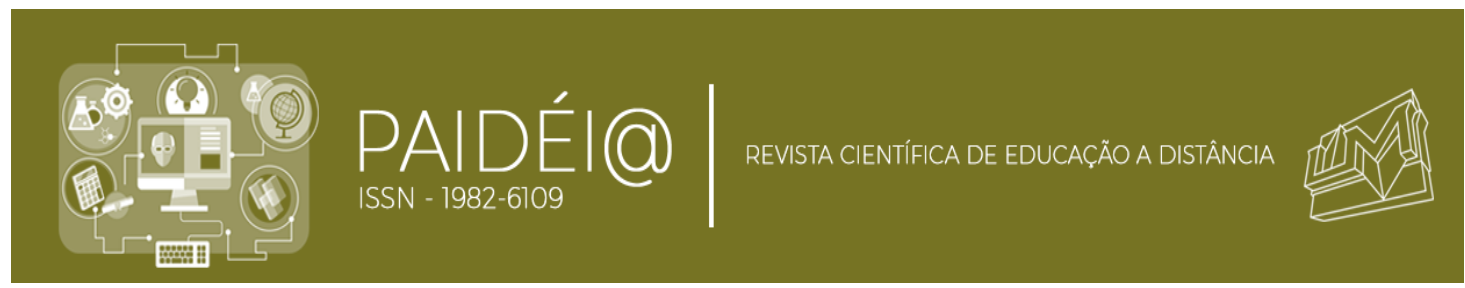

uma base de dados ordenada com todas as respostas obtidas para cada uma das questões do questionário. Nas fases relativas à Decomposição e Recomposição dos dados, de forma interativa entre essas duas fases, foram atribuídos códigos aos dados, tanto em relação aos tipos de interações, como em relação a formação profissional. Em seguida, os dados foram reorganizados e representados através de gráficos. Na fase relativa à Interpretação, foi feito um processo de significação dos dados, dialogando com os referencias teóricos de forma a fundamentar as compreensões estabelecidas. Por fim, na fase relativa à Conclusão, buscouse a luz das interpretações realizadas na fase anterior, extrair conclusões em relação ao engajamento dos estudantes no que diz respeito às Lives, com a indicação de possíveis contribuições e desdobramentos para investigações futuras.

\section{DISCUSSÃO DOS DADOS}

\subsection{O Engajamento na Dimensão Comportamental}

No que segue, serão apresentados e discutidos os dados obtidos sobre o engajamento dos participantes da pesquisa na dimensão comportamental.

\subsubsection{A motivação para a participação em Lives}

No gráfico 1, abaixo, encontram-se os dados obtidos relativos a aspectos que motivam os estudantes a participarem das Lives das disciplinas SEN001 e/ou SCN001.

Gráfico 1 - Aspectos que motivam a participação dos estudantes nas Lives

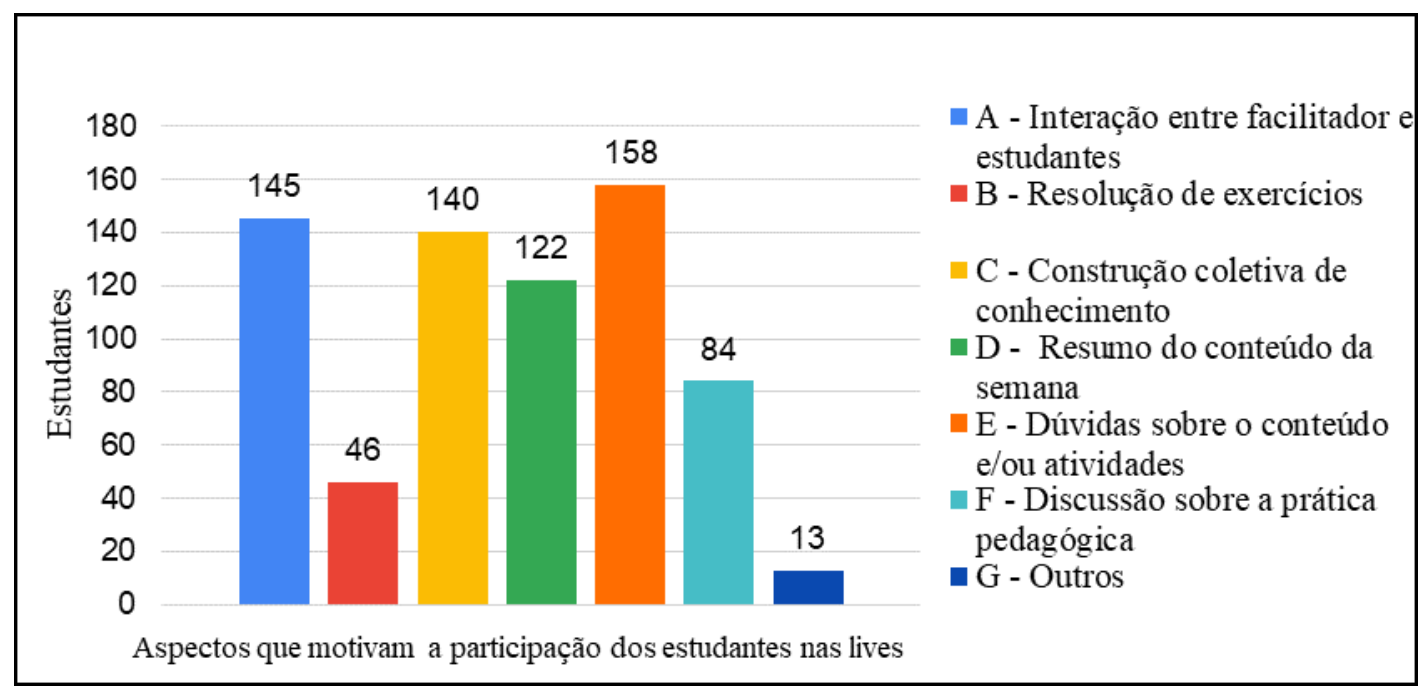

Fonte: Dados da pesquisa 


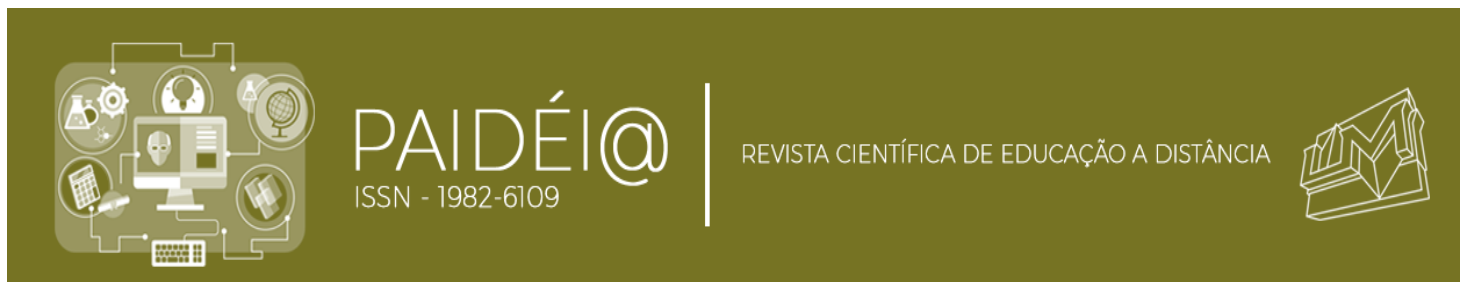

Conforme pode ser observado no gráfico 1, os fatores que mais motivam os estudantes a participarem das Lives, são: Dúvidas sobre o conteúdo elou atividades; Interação entre facilitador e estudantes; Construção coletiva de conhecimento e Resumo do conteúdo da semana. Entre os fatores menos indicados como motivadores, estão: Discussão sobre a prática pedagógica e Resolução de Exercícios. Em "Outros", destacaram-se a indicação de fatores que impossibilitam a participação das Lives, como por exemplo, indisponibilidade no horário, internet limitada ou por motivos de trabalho.

Nesse contexto, aferiu-se que as seguintes interações estão associadas à participação dos estudantes nas Lives: Estudante-Professor/Facilitador, em decorrência da interação entre facilitador e estudante estar entre os principais fatores que motivam a participação; Estudante-Conteúdo, pois os estudantes interagem ativamente com o conteúdo e na ocorrência de dúvidas, indicam que participam das Lives, para discuti-las e saná-las; Estudante-Estudante, proporcionada pela possibilidade de, na participação das Lives, ocorrer construção coletiva de conhecimentos e a própria interação entre os estudantes; e por fim, a Interação Vicária, decorrente de um dos motivos mais indicados para a participação também ser a explanação do facilitador sobre o conteúdo de estudo da semana.

Considerando que a aprendizagem na $\mathrm{EaD}$ é baseada na qualidade das interações e comunicações que efetivamente ocorrem dentro desse contexto educacional, os aspectos que levam os estudantes a participarem da Live revelam uma postura sobre a aprendizagem online (OLIVEIRA; LIMA, 2013). Pautado nos fatores mais indicados, a Live, para esses estudantes se configura como uma oportunidade de interagir com o conteúdo de forma coletiva e síncrona, abrindo espaço ao diálogo crítico e reflexivo.

Algo notório dentro do contexto da formação profissional desses estudantes, foi a relativa baixa associação entre os fatores que motivam a participação em Lives e o fator Discussão sobre a Prática Pedagógica. Esse resultado pode ser um indicativo de que na visão dos estudantes, a Live não é um espaço destinado para discussões sobre a prática pedagógica, ou ainda, pela pouca observância de Lives com essa finalidade e, portanto, a não associação como um dos fatores que mais engajam a participação. A esse respeito, Valente (2010) discute que o principal desafio dessa modalidade de ensino é criar condições que favoreçam processos de construção de conhecimento, em detrimento, de um ambiente exclusivamente associado a transmissão de informação. Mas, no contexto da formação de professores, acrescenta-se que além da construção de conhecimentos, esse desafio também 


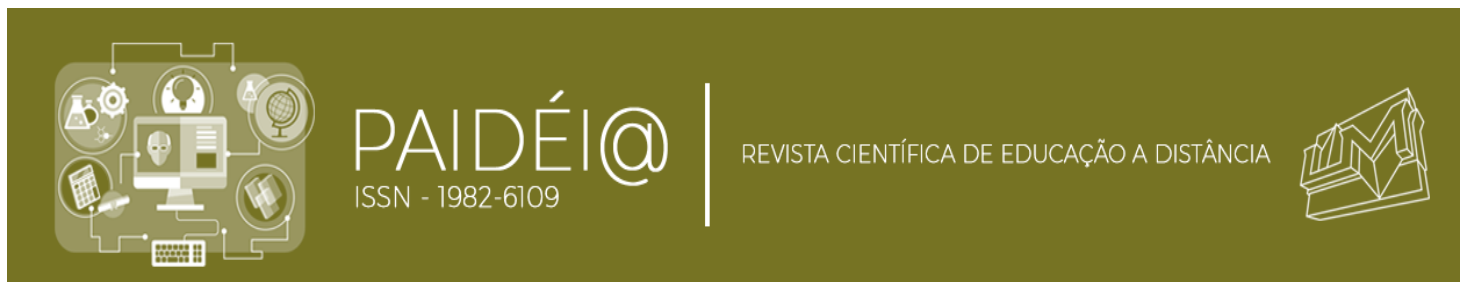

inclui o desenvolvimento de habilidades e atitudes que promovam as competências do perfil profissional.

\subsubsection{As atitudes dos estudantes nas Lives}

No gráfico 2, a seguir, são apresentados os dados obtidos relativos às atitudes dos estudantes na participação das Lives das disciplinas SEN001 e/ou SCN001.

Gráfico 2 - Atitudes dos estudantes na participação das Lives

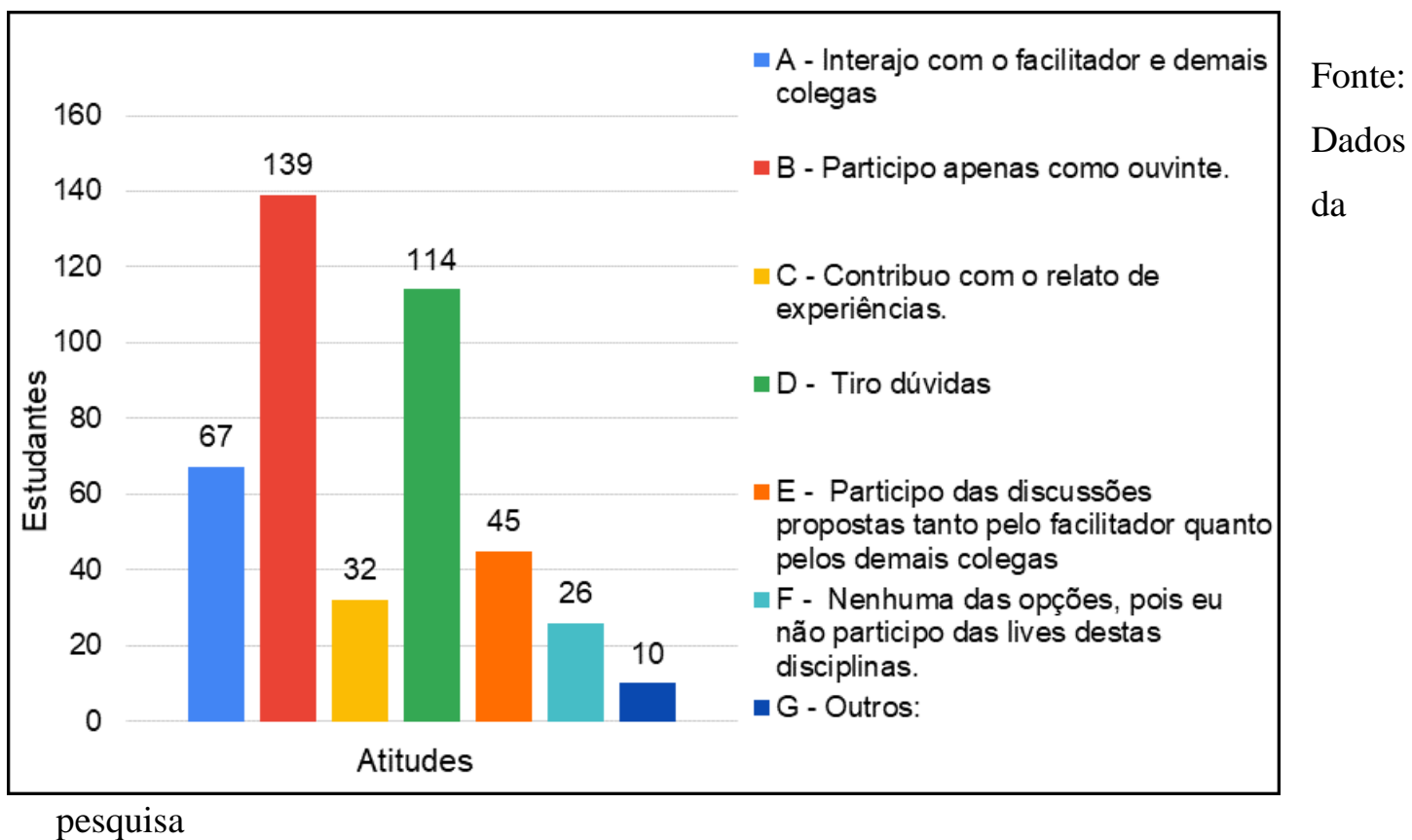

Conforme pode ser observado, nos dados do gráfico 2, as atitudes dos estudantes que mais indicam a sua participação nas Lives, são: participam apenas como ouvinte e tiram dúvidas. Entre as atitudes que menos indicam a participação dos estudantes, estão: interagem com o facilitador e demais colegas; participam das discussões propostas tanto pelo facilitador quanto pelos demais colegas; contribuem com o relato de experiências. Em 'Outros', destacaram-se justificativas como: sempre assistem as Lives gravadas.

Nesse sentido, é possível aferir que, pelas respostas dos alunos ao questionário, ocorrem interações com recursos humanos e não-humanos fazendo uso das Tecnologias Digitais para facilitar a aprendizagem, conforme também mencionou Hirumi (2013). Essas interações observadas ocorrem devido ao interesse dos estudantes em participar das Lives, 


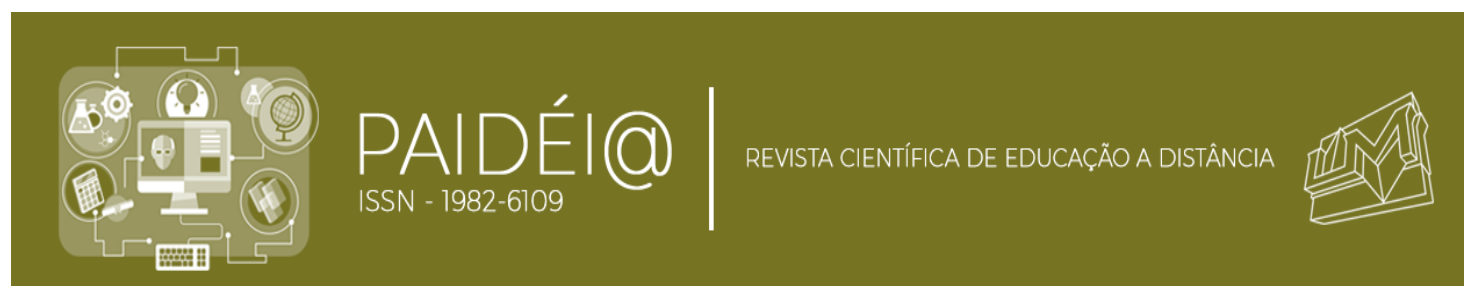

tais como: a Interação Vicária; Interação Estudante-Professor/Facilitador; Interação Estudante-Conteúdo e Interação Estudante-Estudante.

Portanto, a Interação Vicária ocorre quando os estudantes participam como ouvintes nas Lives, conforme indicado por Sutton (2001), mesmo que o estudante não esteja ativamente participando, ele está ouvindo e refletindo sobre o relato dos colegas e do professor/facilitador.

A Interação Estudante-Professor/Facilitador ocorre pela interação entre facilitadorestudante promovida pela realização das Lives nas disciplinas SEN001 e/ou SCN001, na qual Thurmond (2003) constatou como sendo a interação que traz resultado mais significativo aos estudantes. Com esse mesmo pensamento, Yacci (2000) enfatiza a importância do professor realizar feedback imediato aos estudantes e que sem esse loop interativo entre professor/facilitador e estudante a interatividade não ocorre, assim, destacamos que o estudante precisa ter um feedback do professor/facilitador de forma imediata, em princípio, observada quando o estudante busca sanar suas dúvidas ao participar das Lives.

A Interação Estudante-Conteúdo pode ser observada quando o estudante interage com o conteúdo apresentado nas Lives por meio do professor/ facilitador, buscando nesta interação também sanar suas dúvidas ao refletir de forma crítica sobre o conteúdo. Essa interação também foi mencionada por Berge (2002) sobre a necessidade de o estudante refletir sobre o conteúdo.

No caso da Interação Estudante-Estudante, ocorridas tanto nas discussões propostas pelo facilitador quanto pelos demais estudantes contribuindo com o relato de experiências, promovendo a aprendizagem cooperativa e colaborativa, este tipo de interação foi apontada por Berge (2002), quando o estudante cria um sentimento de pertencimento a uma comunidade, no nosso caso, da turma, e assim diminui neles o sentimento que está sozinho no curso, de maneira que o estudante compreenda que os outros colegas estudantes também passam pelas mesmas dificuldades que eles.

A respeito da interação Aluno-Ferramenta, esta foi observada nas atitudes dos estudantes ao assistirem as Lives gravadas, enriquecendo suas experiências no ensino a distância. 


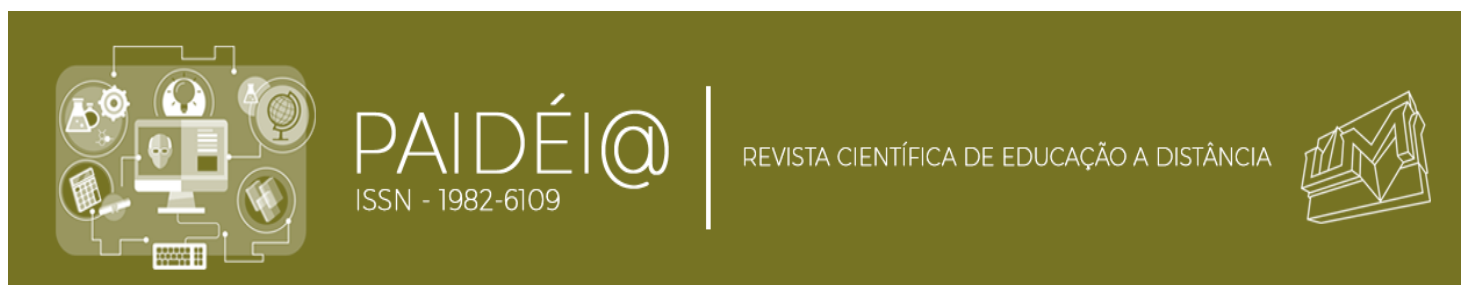

Assim, identificamos os principais tipos de interações que indicam as atitudes dos estudantes na participação das Lives, possibilitando um maior engajamento deles nas disciplinas SEN001 e/ou SCN001.

\subsection{O Engajamento na Dimensão Cognitiva}

Nesta seção, serão apresentados e discutidos os dados obtidos sobre o engajamento dos participantes da pesquisa na dimensão cognitiva.

\subsubsection{A contribuição das Lives para alcançar os objetivos da disciplina SEN001}

O quadro 1 apresenta os objetivos da disciplina SEN001, que foram retirados na integra do plano de ensino do curso de Licenciatura em Pedagogia oferecido pela UNIVESP.

Quadro 1 - Os objetivos da disciplina SEN001

\begin{tabular}{|c|l|}
\hline Objetivos & \multicolumn{1}{c|}{ Objetivos da disciplina de SEN001 } \\
\hline A & $\begin{array}{l}\text { Identificar a importância do ensino da Matemática para a formação crítica da } \\
\text { cidadania. }\end{array}$ \\
\hline B & $\begin{array}{l}\text { Discutir sobre os fundamentos para o ensino da Matemática em consonância } \\
\text { com a sociedade contemporânea. }\end{array}$ \\
\hline
\end{tabular}

Fonte: Plano de ensino do curso de Pedagogia - UNIVESP

O objetivo A aborda uma temática que merece destaque: a formação crítica do cidadão. Entende-se por formação crítica do cidadão ou cidadania crítica na Educação Matemática “o potencial de 'desafiar' a autoridade constituída [...], uma oposição a qualquer decisão considerada inquestionável” (SKOVSMOSE, 2008, p. 94). Nesse viés, o ensino da Matemática tem a função de preparar os estudantes para a superação da submissão, da alienação e das desigualdades.

Com base nesse conceito considera-se necessária à interação dos estudantes com recursos humanos e não-humanos em sua formação, pois essas interações possibilitam a construção de conhecimentos e a formação crítico reflexiva, indispensáveis à formação crítica da cidadania.

O objetivo B ao abordar como temática a consonância do ensino da Matemática com a sociedade contemporânea traz à tona a importância dessa disciplina como parte da comunicação e interação da sociedade. Nesse sentido, discutir os fundamentos para o ensino 


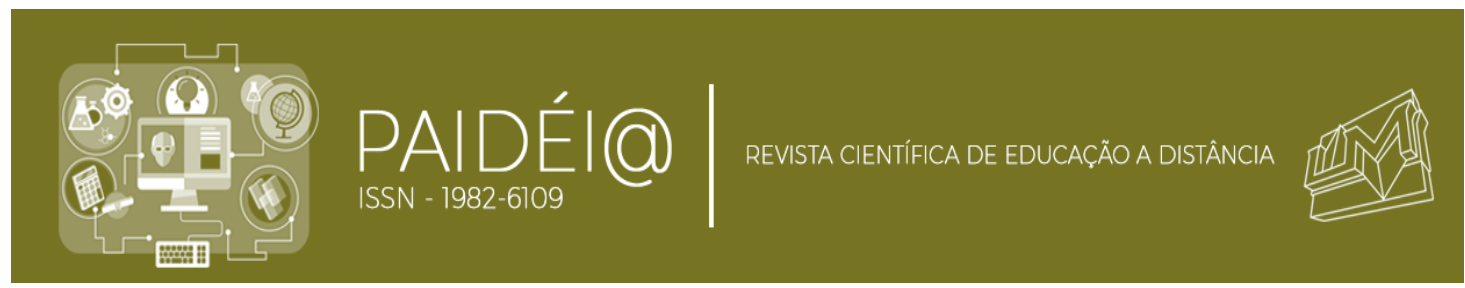

da Matemática requer interações entre sujeitos (interação humana) e interações por meio de ferramentas, conteúdos e diferentes ambientes (interação não-humana).

Com base no que foi descrito, o gráfico 3, a seguir, apresenta os dados obtidos relativo à consideração dos estudantes a respeito da contribuição das Lives para alcançar os objetivos da disciplina SEN001.

Gráfico 3 - Contribuições das Lives para alcançar os objetivos da disciplina SEN001

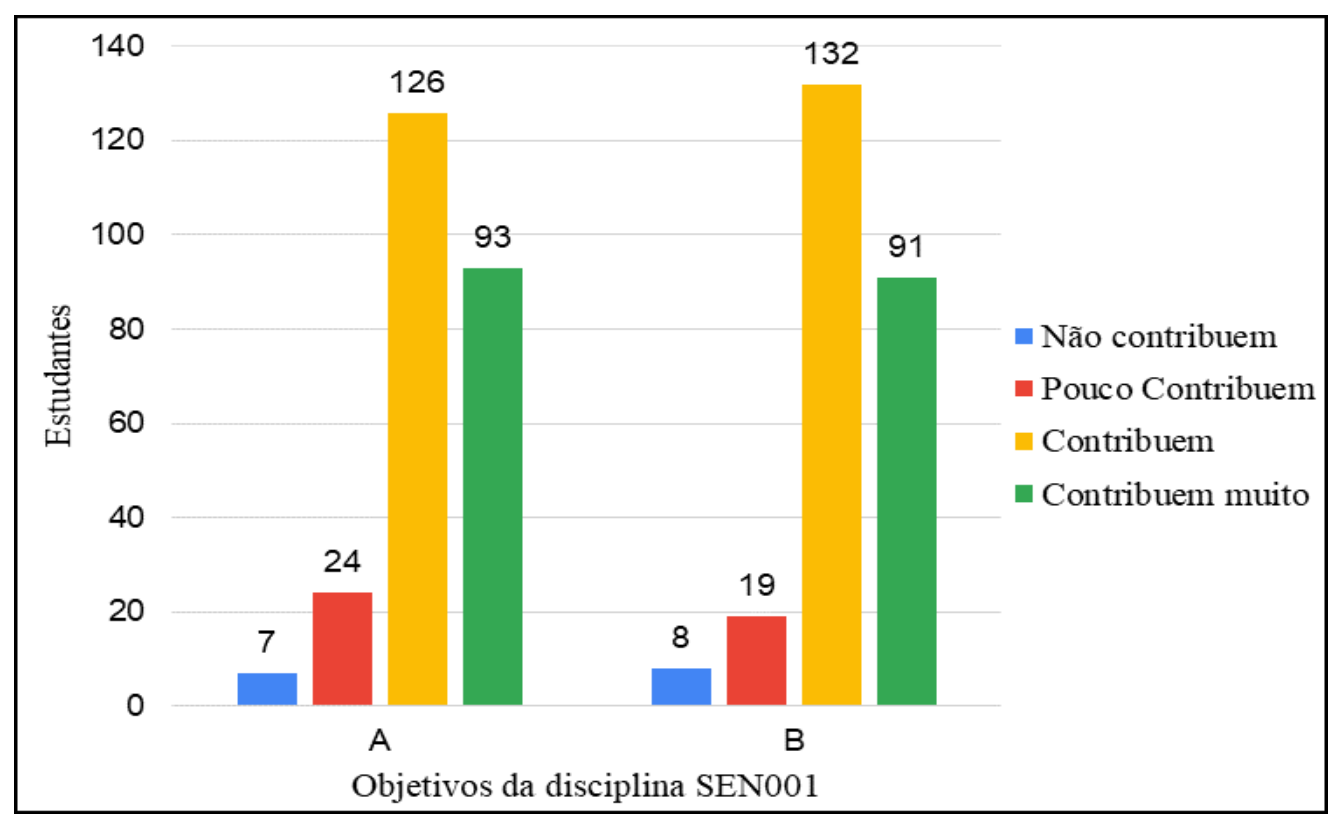

Fonte: Dados da pesquisa

Os dados apresentados no gráfico 3 mostram que os estudantes consideram, em sua maioria, que as Lives contribuem ou contribuem muito para alcançar os objetivos da disciplina SEM001. Isso porque as Lives possibilitam que as interações humanas e não humanas sejam possíveis, desde o momento em que o estudante tem o contato com o conteúdo até o momento em que suas dúvidas, percepções, conclusões acerca do que estudou emergi no diálogo estabelecido entre os participantes da Live. Nesse sentido, considerar a Live como um meio de contribuição para atingir os objetivos da disciplina é considerar que todas as formas de interação humanas e não humanas foram empregadas.

Por outro lado, os estudantes que consideraram que as Lives não contribuem ou pouco contribuem para que os objetivos da disciplina sejam alcançados, podem não ter conseguido interagir com outros estudantes ou com o facilitador nas Lives (interações estudanteestudante e estudante-facilitador). Assim como, o estudante pode não ter conseguido interagir com as ferramentas (interação estudante-ferramentas) ou não ter sido compreendido 


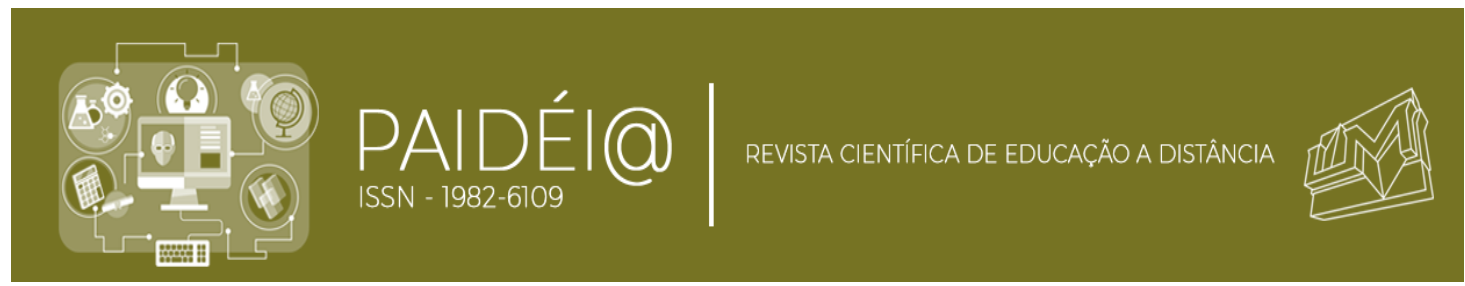

como sujeito ativo que assume uma posição crítica frente ao conteúdo (interação estudanteconteúdo).

\subsubsection{A contribuição das Lives para alcançar os objetivos da disciplina SCN001}

O quadro 2 apresenta os objetivos da disciplina SCN001, que foram retirados na íntegra do plano de ensino do curso de Licenciatura em Pedagogia oferecido pela UNIVESP.

Quadro 2 - Os objetivos da disciplina SCN001

\begin{tabular}{|c|l|}
\hline Objetivos & \multicolumn{1}{|c|}{ Objetivos da disciplina de SCNO01 } \\
\hline C & $\begin{array}{l}\text { Introduzir discussões relacionadas às ciências naturais, visando apresentar seus } \\
\text { mecanismos de funcionamento e suas relações com a tecnologia e a sociedade. }\end{array}$ \\
\hline D & $\begin{array}{l}\text { Favorecer a compreensão do processo histórico de desenvolvimento da ciência e sua } \\
\text { relação com as dimensões política, social, ética e econômica. }\end{array}$ \\
\hline E & $\begin{array}{l}\text { Permitir que os Estudantes estabeleçam uma relação próxima com o conhecimento } \\
\text { científico, para que façam uma relação com o ensino de ciências. }\end{array}$ \\
\hline F & $\begin{array}{l}\text { Estimular a apropriação crítica desse conhecimento, valorizando a reflexão dos Estudantes } \\
\text { com relação ao impacto da ciência e da tecnologia no contexto da sociedade do } \\
\text { conhecimento. }\end{array}$ \\
\hline G & $\begin{array}{l}\text { Promover discussões sobre a questão dos métodos, condições sociais e culturais de } \\
\text { produção do conhecimento científico e sua relação com o ensino de ciências. }\end{array}$ \\
\hline H & \begin{tabular}{l} 
Compreender aspectos históricos e metodológicos do ensino de ciências. \\
\hline
\end{tabular}
\end{tabular}

Fonte: Plano de ensino do curso de Pedagogia - UNIVESP.

Os objetivos listados no quadro 2 , ressaltam a intenção da disciplina de oportunizar aos estudantes a reflexão sobre a ciência como uma construção humana destacando seus mecanismos de funcionamento suas virtudes e limitações, permitindo assim uma apropriação crítica por parte dos estudantes desse conhecimento, na compreensão da complexidade do mundo que os cercam de forma consciente.

Essa preocupação é pautada devido à polivalência que esses futuros professores irão exercer nos anos iniciais e ser este, o primeiro contato que seus futuros alunos terão com os conhecimentos científicos de forma sistematizada, o que segundo Carvalho (1998) influenciará a aprendizagem subsequente em relação ao conhecimento científico.

Com base no que foi descrito, o gráfico 4, a seguir, apresenta os dados obtidos relativo à consideração dos estudantes a respeito da contribuição das Lives para alcançar os objetivos da disciplina SCN001. 


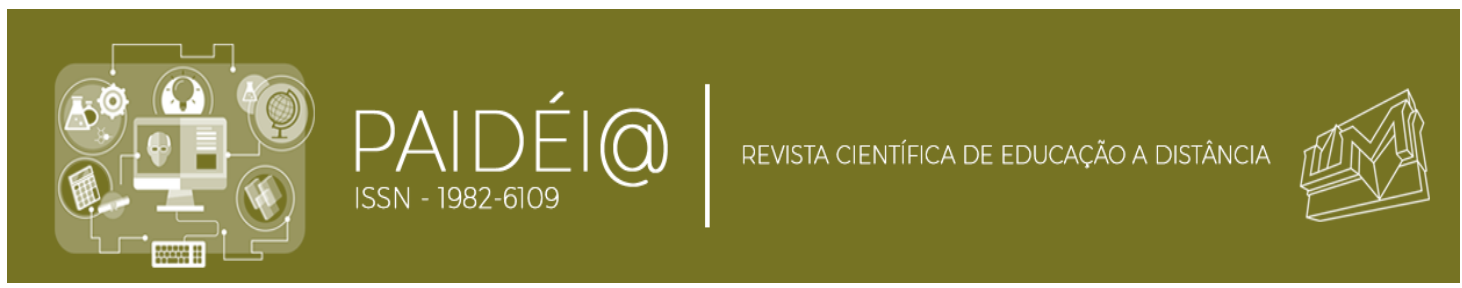

Gráfico 4 - Contribuições das Lives para alcançar os objetivos da disciplina SCN001

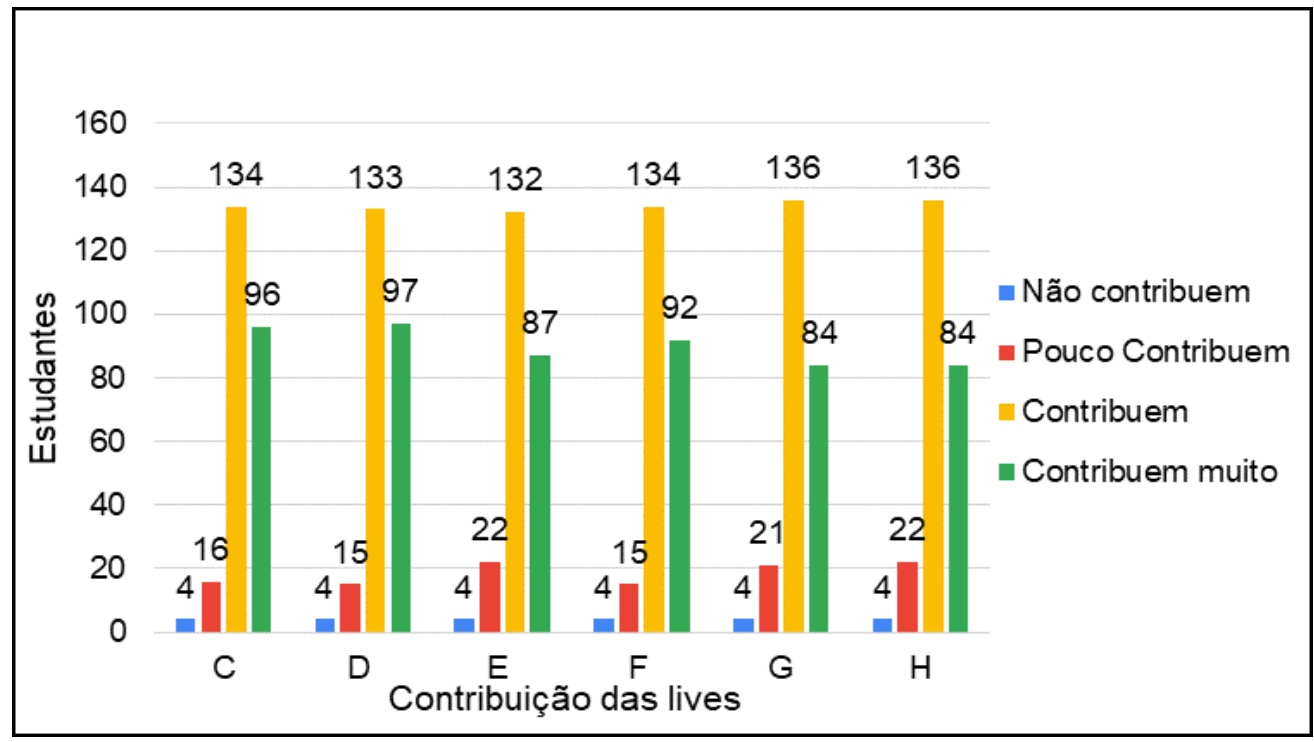

Fonte: Dados da pesquisa

Os dados apresentados no gráfico 4 mostram que os estudantes consideram, em sua grande maioria, que as Lives contribuem ou contribuem muito para alcançar todos os objetivos da disciplina SCN001. Consideramos que esse fato é devido a interações humanas que são proporcionadas pelas Lives. É nesse momento que a interação entre os estudantes, facilitadores, professores são estabelecidas e as trocas de informações e reflexões contribuem não só para a aquisição de conceitos, mas para aprenderem a pensar cientificamente e criticamente. Assim como, para que os estudantes construam sua concepção de ciência, o que vai influenciar sua futura prática docente, conforme explicitam Gil-Pérez et al (2001) e Cachapuz et al (2011), ao ressaltarem que as concepções de ciências que os professores possuem vão ter implicações diretas ou indiretas na maneira como irão ensinar ciências.

Ponderando que, alguns cursos de pedagogia podem vir a não privilegiar discussões epistemológicas sobre a ciência, as interações humanas estabelecidas nas Lives podem propiciar uma direção reflexiva, dando oportunidade para que os estudantes possam tomar consciência das suas próprias concepções epistemológicas, dando início assim a uma (re)construção das identidades profissionais polivalentes como professores que ensinam ciências a partir de uma imagem adequada da mesma.

\subsubsection{A contribuição das Lives para a formação docente}




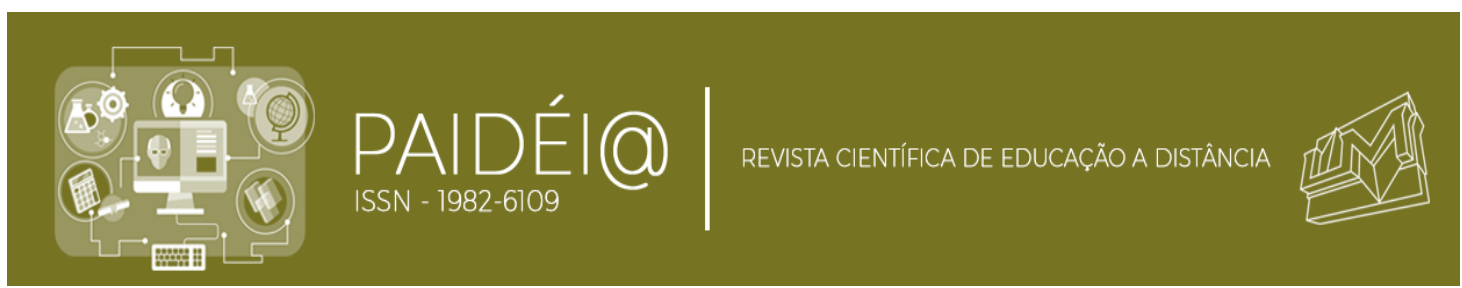

No gráfico 5, a seguir, são apresentados os dados obtidos sobre aspectos relacionados a contribuição das Lives para a formação docente.

Gráfico 5 - Contribuição das Lives para a formação docente

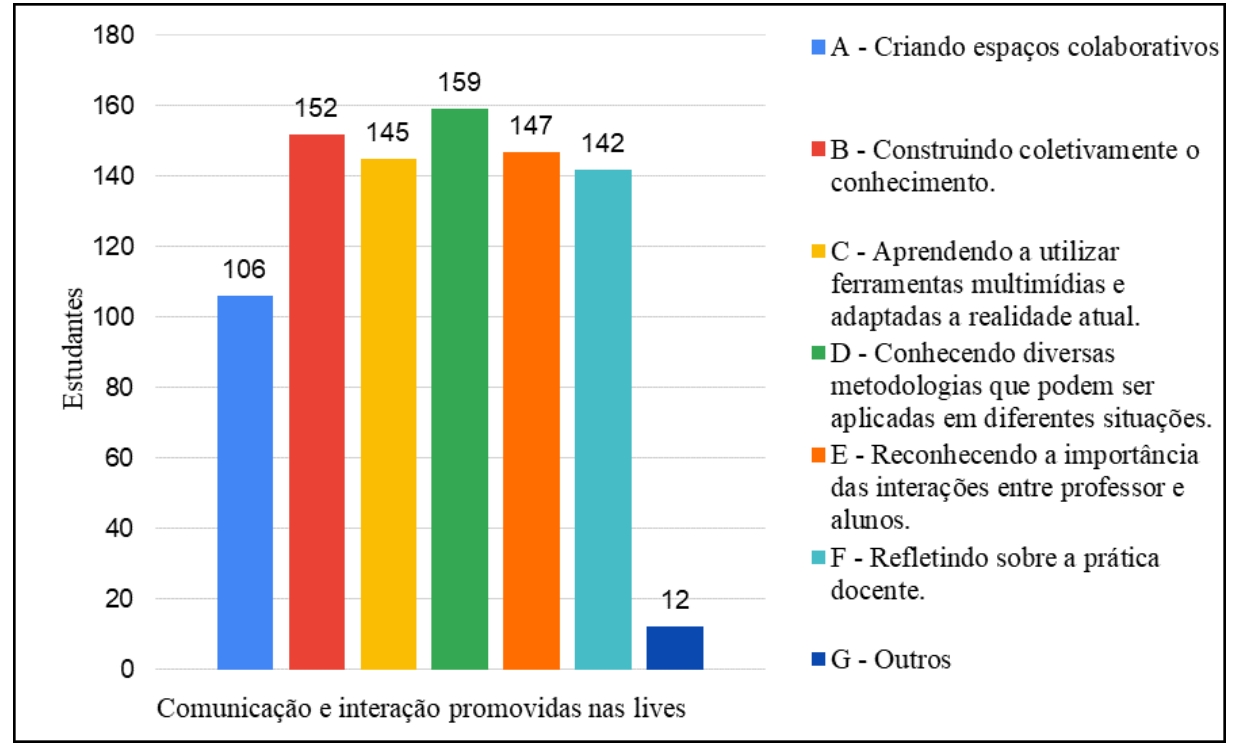

Fonte: Dados da pesquisa

Conforme pode ser observado, quase todos os fatores foram associados pelos estudantes como fatores que contribuem, ou poderiam contribuir, especificamente para a formação docente. A exceção ocorreu apenas em relação a Criando espaço colaborativos, que foi o fator com menos indicações, quando comparado com os demais. Isso pode ter ocorrido porque na opinião desses estudantes, as Lives não propiciam a criação de espaços colaborativos ou porque apenas a criação de espaços colaborativos não contribui diretamente para a formação docente, como os demais fatores apresentados na questão, contribuem ou podem contribuir.

Entretanto, destaca-se que em um espaço colaborativo, o coletivo reflete de forma conjunta sobre os mais variados temas, assim como também há a produção de conhecimento, por meio das discussões e dos questionamentos de cada um e do grupo, concordando, revendo e construindo conhecimentos através de reflexões coletivas (OLIVEIRA; LIMA, 2013). Portanto, essa característica relacionada a espaços colaborativos permeia várias competências, e de forma mais específica, habilidades apresentadas nas DCN para a Formação Inicial de Professores da Educação Básica. Em Outros, destacaram-se justificativas em relação a não participação de Lives e respostas indicando o papel do estudante nas Lives, de forma a contribuir para que ela seja um espaço de formação docente. 


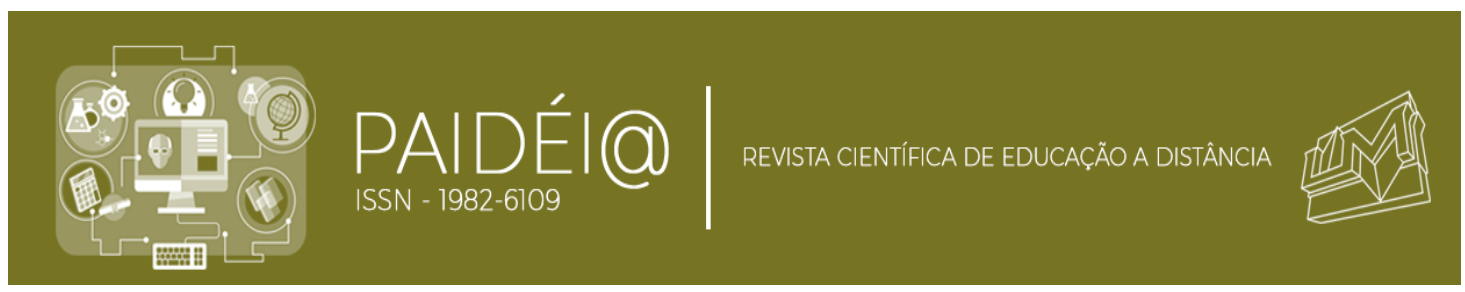

Dessas observações, é possível aferir que na opinião desses estudantes, as interações do tipo: Estudante-Professor/Facilitador, pelo fato das Lives propiciarem vivências associadas aos modos de interação entre professor e estudante; Estudante-Estudante, devido ao espaço das Lives possibilitarem a construção coletiva de conhecimentos; EstudanteFerramenta, pela mobilização de diferentes ferramentas multimídias para acessar e participar das Lives; e Interação Vicária, devido ao contato com diferentes metodologias; contribuem para a formação docente e que, ou já são exploradas, ou poderiam ser exploradas na realização de Lives.

Por fim, nesse contexto de formação profissional, o que se interpreta é que esses estudantes demonstram compreensão e interesse em obter uma formação mais direcionada ao desenvolvimento de competências, contemplando a aquisição, não só de conhecimentos, mas também de habilidades e de atitudes. Também dão importância à reflexão sobre a prática docente, ainda que, conforme aferido na análise dos dados relativos à motivação dos estudantes, esse seja o aspecto que menos motive a participação das Lives. Essa, aparente contradição, talvez possa ser compreendida pelo ponto de vista de que, nas Lives, ainda não se observe tal característica, ou seja, ainda seja um espaço pouco direcionado, de forma específica e na opinião desses estudantes, para a formação docente.

\subsection{Engajamento na dimensão emocional}

Nesta seção, serão apresentados e discutidos os dados obtidos sobre o engajamento dos participantes da pesquisa na dimensão emocional.

\subsubsection{Experiências marcantes de estudantes em Lives}

$\mathrm{Na}$ dimensão emocional a questão proposta solicitou que os estudantes relatassem uma experiência marcante nas Lives. Nas respostas apresentadas observou-se a presença dos diferentes tipos de Interações Humanas e Não-humanas. Essas interações foram evidenciadas em afirmações do tipo:

(1) "As lives são uma boa forma de interagir com os outros estudantes e de tirar dúvidas com o (a) facilitador".

(2) "Às vezes temos uma dúvida e quando descobrimos através das lives que mais pessoas também têm o mesmo problema, fica mais fácil as soluções em conjunto".

(3) "Quando algum participante relata um fato que aconteceu no cotidiano fazendo analogias com o conteúdo estudado ajuda a compreender melhor a prática". 


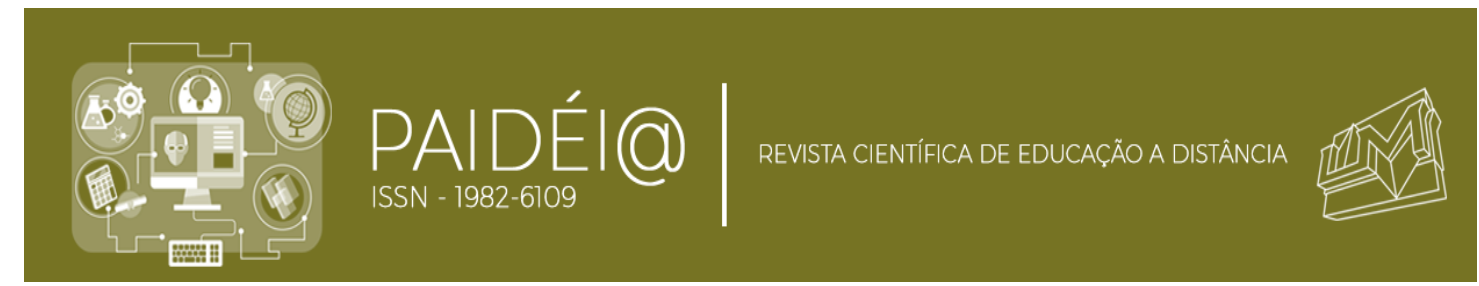

(4) "A live com a participação do professor inspirou muitas perguntas autênticas dos alunos, permitindo a exposição do entendimento de cada um (a).

(5) "A troca de experiências, o compartilhamento de saberes diferentes, a construção do respeito mútuo e o aprendizado constante”.

(6) "Poder compartilhar ideias e tirar dúvidas, interagindo ora com os facilitadores e os outros alunos, que não necessariamente são do seu polo e curso”.

(7) "Ouvir os facilitadores falando sobre o conteúdo, eles nos auxiliam a concretizar o aprendizado".

(8) "Poder compartilhar experiências e conhecimentos com os professores em questão e até mesmo com os alunos de polos diferenciados".

No que tange a interação Estudante-Professor/Facilitador é comum nas afirmações (1), (4), (5), (6) e (8). Os estudantes ao relatarem que as Lives são uma forma de interagir com facilitadores ou professores, que a participação do professor inspira muitas perguntas e que nelas há o compartilhamento de saberes diferentes, deixaram evidente esse tipo de interação. Além disso, a interação Estudante-Estudante se faz presente nas afirmações (1), (2), (3), (4), (5), (6) e (8). Nestas, observa-se que a Live é vista como um espaço de interação com outros estudantes, por meio de trocas de experiências, de dúvidas comuns, de relatos cotidianos, do compartilhamento de ideias e saberes. Elementos essenciais e indispensáveis para uma interação humana.

A respeito da interação Estudante-Outros, que compõe os tipos de interação humana, identificamos sua presença nas afirmações (6) e (8). Tal interação é constatada quando os estudantes relatam que interagiram com estudantes de outros polos, pois entende-se tal interação como todas as interações que um estudante pode ter com pessoas de fora do curso, de outras instituições. Nesse caso, compreende-se que o fato de os estudantes serem de polos distintos não há com frequência uma interação entre eles, portanto, visualiza-se essa interação como Estudante-Outros. Mas, não se descarta a hipótese de outras percepções que identificam tais afirmações como características de interações Estudante-Estudante.

As relações estabelecidas por meio das Lives além de possibilitarem as interações humanas são substanciadas pelas Interações Não-humanas. Isso, pois, todo o processo de trocas de experiências, de compartilhamento de saberes, de tirar dúvidas sobre conteúdos e questões, de analogias do conteúdo, entre outros pontos indicados nas respostas dos estudantes, tem como base as interações Estudante-Conteúdo, Estudante-Ambiente e Estudante-Ferramenta. Estudante-Conteúdo, pois ao tirar dúvidas e ao fazer analogias ao conteúdo o estudante teve ou está tendo no momento da Live contato com o conteúdo. 


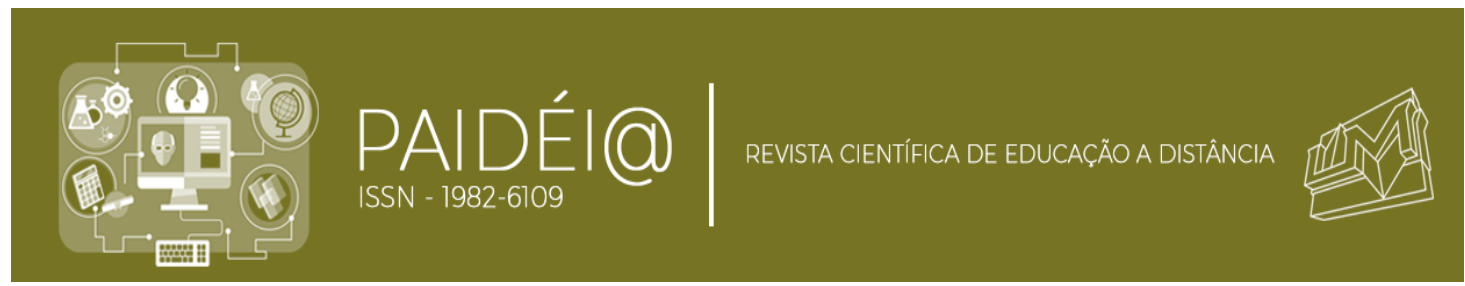

Estudante-Ambiente porque ao trocar experiências pode relatar vivências em outros ambientes, como seu ambiente de trabalho, o ambiente de estágio, entre outros. E, a interação Estudante-Ferramenta, é identificada na própria Live, por se tratar de uma ferramenta que os estudantes mobilizam dentro ou fora do AVA em prol da construção de aprendizagens.

Por fim, pela experiência que as autoras deste artigo possuem enquanto facilitadoras e mediadoras de Lives, afirma-se que a Interação Vicária também é uma interação comum nas Lives, pois muitos estudantes apesar de não participarem ativamente das interações, observam e absorvem o que está sendo apresentado e discutido nesse espaço. Tal fato pode ser identificado na afirmação (7).

Diante das análises, considera-se que a Live é um espaço de possiblidades. Enquanto ferramenta de comunicação síncrona possibilita que todas as interações se manifestem.

\section{CONSIDERAÇÕES FINAIS}

Nesse estudo buscou-se discutir que fatores estão associados ao engajamento dos licenciandos de pedagogia na comunicação e interação em Lives, considerando a importância dessa interação para o processo de construção de conhecimentos na Educação a Distância (EaD) e no desenvolvimento de habilidades e atitudes que promovam as competências necessárias ao futuro professor. Para tal, considerou-se três tipos de dimensões normalmente associadas ao engajamento estudantil: dimensão comportamental, cognitiva e emocional.

Na dimensão comportamental, os fatores de engajamento dentre os que motivam os estudantes a participarem das Lives são: Dúvidas sobre o conteúdo elou atividades; Interação entre facilitador e estudantes; Construção coletiva de conhecimento e Resumo do conteúdo da semana. Portanto, aferiu-se nesse contexto, que interações do tipo: EstudanteProfessor/Facilitador; Estudante-Conteúdo; Estudante-Estudante e Interação Vicária, são os principais tipos de interações que motivam a participação dos estudantes nas Lives. Com base nesses fatores, podemos dizer que a Live para esses estudantes se configura como uma oportunidade de o estudante interagir com o conteúdo de forma coletiva e síncrona, abrindo espaço ao diálogo crítico e reflexivo.

No que diz respeito as atitudes dos estudantes na participação das Lives foram identificadas como fatores de engajamento: a participação apenas como ouvinte e para tirar dúvidas. Assim, nessas atitudes identificamos os principais tipos de interações, tais como: a 


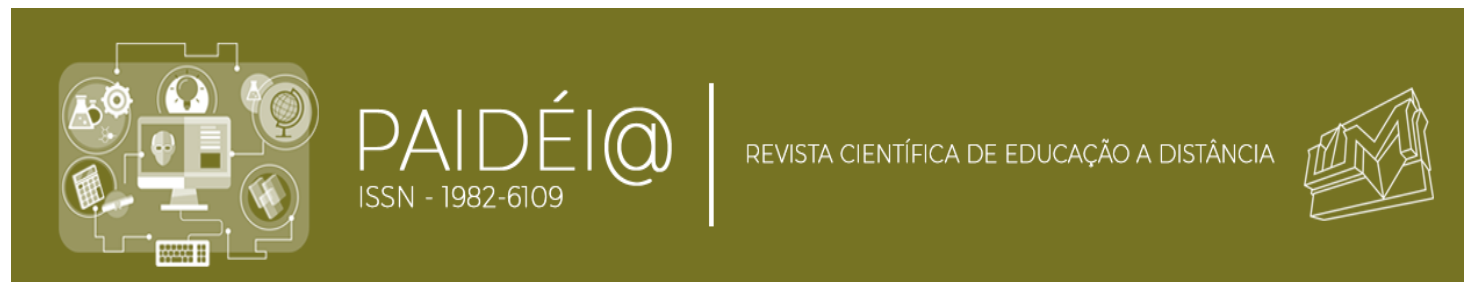

Interação Vicária; Interação Estudante-Professor/Facilitador; Interação EstudanteConteúdo e Interação Estudante-Estudante. Portanto, essas interações possibilitou um maior engajamento deles nas disciplinas.

Na dimensão cognitiva, o engajamento dos estudantes decorre tanto das interações humanas, como não-humanas, proporcionadas nesse ambiente, com maior destaque para as interações humanas. Dentre os fatores relacionados as interações humanas, destacam-se a Construção coletiva do conhecimento, o Reconhecimento da importância relação professoraluno e a Reflexão sobre a prática docente. Os fatores relacionados a interações nãohumanas estão associados a Utilização de ferramentas multimidias, e o Contato com metodologias para a prática docente. Dessa forma, pautado nos fatores mais indicados, a Live para estes estudantes se configura como uma oportunidade de o estudante interagir com o conteúdo de forma coletiva e síncrona, abrindo espaço ao diálogo crítico e reflexivo e para o pensar cientificamente, justificando-se assim o porquê, de forma geral as Lives na opinião destes estudantes, contribuem para alcançar os objetivos das duas disciplinas.

Na dimensão emocional, o engajamento dos estudantes para participarem das Lives é decorrente tanto da interação humana quanto a interação não-humana de acordo com os relatos de experiências marcantes. Destacamos aqui a interação humana, visto que, para tais estudantes as Lives são um espaço de interação com outros estudantes, através das trocas de experiências, de dúvidas comuns, de relatos cotidianos, do compartilhamento de ideias e saberes, características das interações humanas.

Observado os principais fatores que promovem o engajamento dos estudantes em cada uma das três dimensões, no contexto da formação profissional docente, pôde-se concluir que os estudantes buscam por meio de suas participações nas Lives uma formação mais direcionada ao desenvolvimento de competências, contemplando a aquisição, não só de conhecimentos, mas também de habilidades e de atitudes, assim como também buscam refletir coletivamente sobre a prática docente.

Mas por outro lado, a baixa indicação do fator Discussão sobre a Prática Pedagógica na dimensão comportamental, especificamente sobre aspectos que motivam a participação dos estudantes nas Lives, revela que possivelmente este ambiente ainda seja um espaço pouco direcionado, de forma específica e na opinião desses estudantes, para a formação profissional em um âmbito mais prático, tal como vislumbram ser possível. 


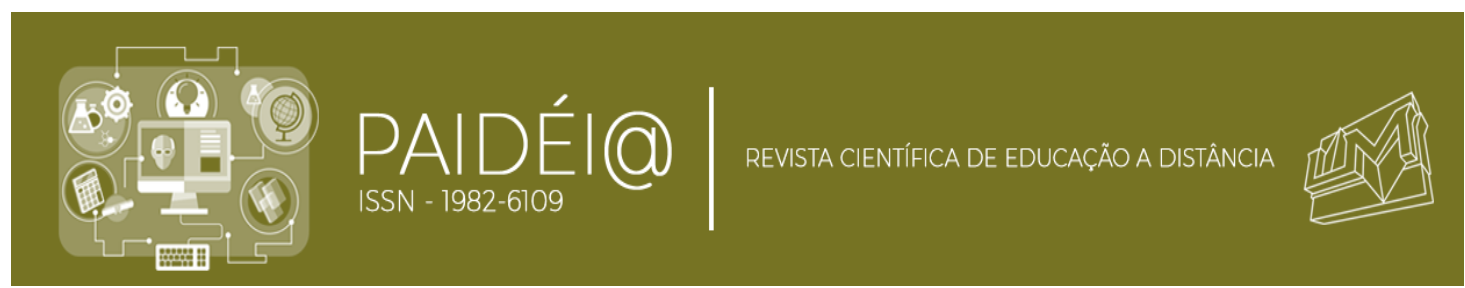

Uma vez que estudos sobre engajamento estudantil contribuem para a avaliação do sucesso acadêmico em atividades oportunizadas aos estudantes, os resultados obtidos nesse estudo indicam as potencialidades das Lives para a formação profissional docente na EaD, mas demandam também um olhar mais atento para que efetivamente o espaço das Lives seja reconhecido e utilizado pelos estudantes para tal finalidade.

\section{REFERÊNCIAS}

ALRASHIDI, O.; PHAN, H. P.; NGU, B. H. Academic Engagement: An Overview of Its Definitions, Dimensions, and Major Conceptualisations. International Education Studies, v. 9, n. 12, p. 41-52, 2016. Disponível em: http://www.ccsenet.org/journal/index.php/ies/article/view/60095

ARAÚJO, A. M. Sucesso no ensino superior: uma revisão e conceptualização. Revista de Estudios e Investigación em Psicología y Educación. v. 4, n. 2, p. 132-141, 2017. Disponível em: https://dialnet.unirioja.es/servlet/articulo?codigo=6241243

BERGE, Z. L. Active, interactive, and reflective learning. The Quarterly Review of Distance Education, v. 3, n. 2, p. 181-190, 2002. Disponível em: https://www.researchgate.net/publication/234737912_Active_Interactive_and_Reflective_ eLearning

BRASIL. Ministério de Educação e Cultura. LDB - Lei n 9394/96, de 20 de dezembro de 1996. Estabelece as diretrizes e bases da Educação Nacional. Brasília: MEC, 1996.

Ministério da Educação. CNE/CEB. Diretrizes Curriculares Nacionais e Base Nacional Comum para a Formação Inicial e Continuada de Professores da Educação Básica. Brasília, 2019.

CACHAPUZ, A.; GIL-PÉREZ, D.; CARVALHO, A. M. P.; PRAIA, J.; VILCHES, A. A necessária renovação do Ensino das Ciências. 3. ed. São Paulo: Cortez, 2011.

CARVAlHO, A. M. P. Ciências no Ensino Fundamental - O conhecimento físico. São Paulo: Scipione, 1998.

GIL-PÉREZ, D., CACHAPUZ, A., MONTORO, I. F., ALIS, J. C., E PRAIA, J. Para uma imagem não deformada do trabalho científico. Revista Ciência e Educação, Bauru, v. 7, n. 2, p. 125-153, 2001. Disponível em: https://www.scielo.br/pdf/ciedu/v7n2/01.pdf

HEDGES, L. V. How Large Are Teacher Effects? Educational Evaluation and Policy Analysis, v. 26, n. 3, p. 237-257, 2004. Disponível em: https://journals.sagepub.com/doi/10.3102/01623737026003237 


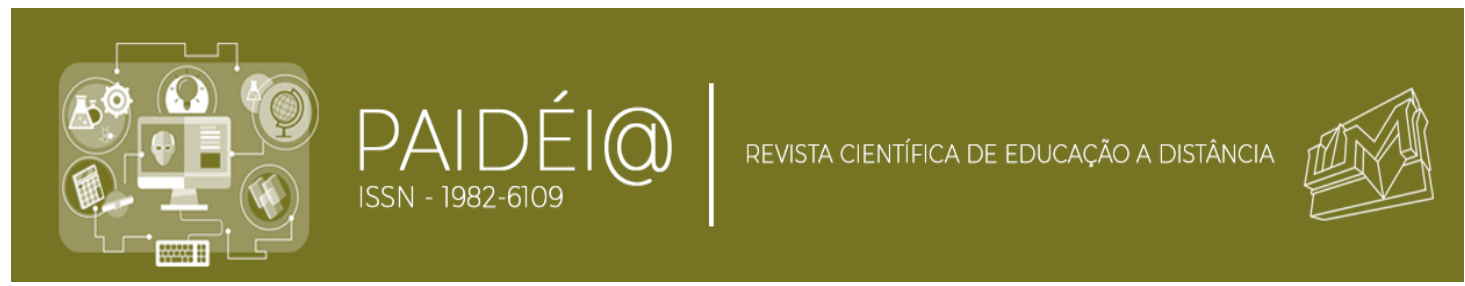

HILLMAN, D. C.; WILLIS, D. J.; GUNAWARDENA, C. N. Learner-interface interaction in distance education: An extension of contemporary models and strategies for practitioners. The American Journal of Distance Education, v. 8, n. 2, p. 30-42, 1994. Disponível em: https://www.tandfonline.com/doi/abs/10.1080/08923649409526853

HIRUMI, A. Three levels of planned elearning interactions: A framework for grounding research and the design of e-learning programs. Quarterly Review of Distance Education, v. 14, n. 1, p. 1-16, 2013. Disponível em: https://eric.ed.gov/?id=EJ1144784

MARTINS, A. B. J.; JUSTINO, A. C. F. C.; GABRIEL G. C. F. SBIDM: comunicação síncrona, assíncrona e multidireccional. Serviços de Bibliotecas, Informação Documental e Museologia da Universidade de Aveiro Campus universitário de Santiago, 2010.

Disponível em: https://www.bad.pt/publicacoes/index.php/congressosbad/article/view/209

MARTINS, D. S., PIMENTEL, M. G. C. TV digital e a EAD. In: LITTO, F. M., FORMIGA, M. (Orgs.). Educação a distância: o estado da arte. São Paulo: Pearson Education do Brasil, 2012.

MARTINS, A. S. R.; QUINTANA, A. C.; QUINTANA, C. G. O uso da webconferência na disseminação e avaliação do conhecimento em $\mathrm{EaD}$ : relato de experiência. Revista Paidéi@. Unimes Virtual, v. 12, n. 21, p. 181-193, jan. 2020. Disponível em: https://periodicos.unimesvirtual.com.br/index.php/paideia/article/view/968

MARTINS, L. M. de; RIBEIRO, J. L. D. Engajamento do estudante no ensino superior como indicador de avaliação. Avaliação (Campinas), v. 22, n. 1, p. 223-247, abr. 2017. Disponível em: https://www.scielo.br/pdf/aval/v22n1/1982-5765-aval-22-0100223.pdf

MILL, D. Educação a Distância Contemporânea: noções introdutórias. In: OTSUKA, J. L.; MILL, D.; OLIVEIRA, M. R. G. (Orgs). Educação a Distância: formação do estudante virtual. São Carlos: EDUFSCar, 2013, p. 15-30.

MOORE, M. G. Editorial: Three types of interaction. American Journal of Distance Education, v. 3, n. 2, p. 1-6, 1989. Disponível em:

https://www.tandfonline.com/doi/abs/10.1080/08923648909526659

OLIVEIRA, M. R.; LIMA, V. S. O estudante da EaD: seu papel e sua organização para o estudo. In: OTSUKA, J. L.; MILL, D.; OLIVEIRA, M. R. G. (Orgs.). Educação a Distância: formação do estudante virtual. São Carlos: EDUFSCar, 2013, p. 61-76. RIBEIRO, G. M. Educação a distância: interação e abordagens contemporâneas. Revista Eletrônica Científica Ensino Interdisciplinar. Mossoró, v. 5, n. 14, out. 2019.

RIGO, R. M.; MOREIRA, J. A.; VITÓRIA, M. I. Engagement acadêmico: retrospectiva histórica (diferentes níveis, distintas consequências e responsabilidades). In: RIGO, R. M.; MOREIRA, J. A.; VITÓRIA, M. I. (Orgs.). Promovendo o engagement estudantil na educação superior: reflexões rumo a experiências significativas e integradoras. Porto Alegre: EDIPUCRS, 2018, p. 15-34. 


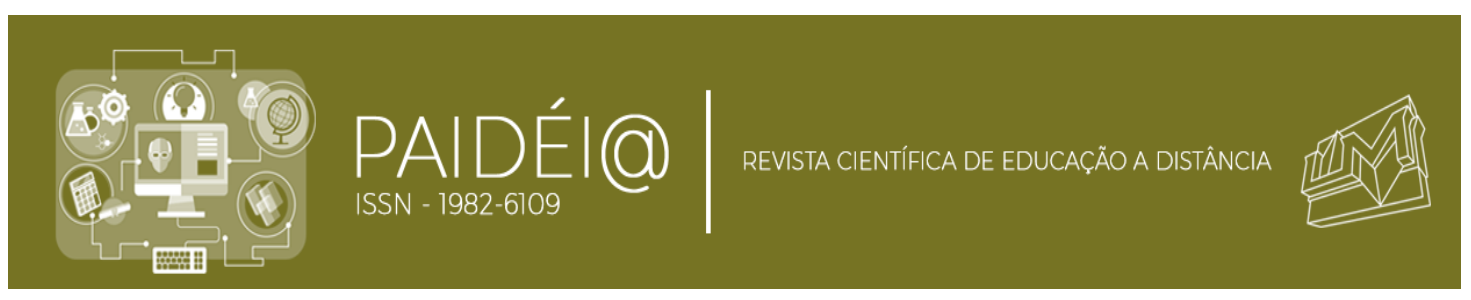

SKOVSMOSE, O. Desafios da Reflexão em Educação Matemática Crítica. CampinasSP: Papirus, 2008.

SUTTON, L. A. The principle of vicarious interaction in computer-mediated communications. International Journal of Educational Telecommunications, v. 7, n. 3, p. 223-242, 2001. Disponível em: https://www.learntechlib.org/primary/p/9534/

THURMOND, V. A. Examination of interaction variables as predictors of students' satisfaction and willingness to enroll in future web-based courses while controlling for student characteristics. 2003. Tese (Doutorado) - University of Kansas, 2003.

VALENTE, J. A. O papel da interação e as diferentes abordagens pedagógicas de educação a distância. In: MILL, D.; PIMENTEL, N. (Orgs.). Educação a distância: desafios contemporâneos. São Carlos: EdUFSCar, 2010, p. 25-42.

YACCI, M. Interactivity demystified: A structural definition for online learning and intelligent CBT. Educational Technology, v. 40, n. 4, p. 5-16, 2000. Disponível em: https://esoluk.co.uk/calling/pdf/Yacci_interactivity_demystified.pdf

YIN, R. K. Pesquisa qualitativa do início ao fim. Porto Alegre: Penso, 2016. 


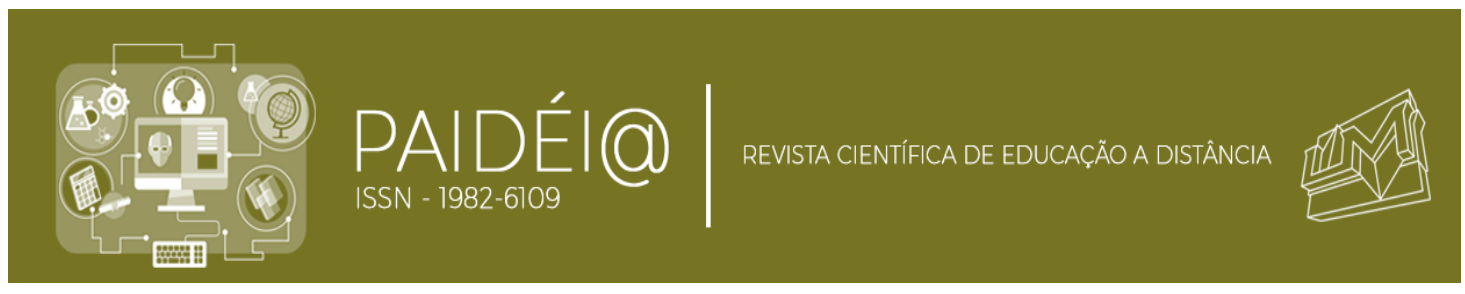

\section{Fabiana Santos Cotrim}

Mestra em Matemática pela Universidade Federal de São Carlos (UFSCAR). Doutoranda em Ensino de Ciências e Matemática pela Universidade Estadual de Campinas (UNICAMP). Professora da UFSCAR - Campus Lagoa do Sino.

\section{Lilian Patrícia Lima}

Mestra em Ensino de Ciências pela Universidade de São Paulo (USP). Doutoranda em Ensino de Ciências e Matemática pela Universidade Estadual de Campinas (UNICAMP).

\section{Mariana dos Santos Cezar}

Mestra em Educação em Ciências e Matemática pelo Instituto Federal do Espírito Santo (IFES). Doutoranda em Ensino de Ciências e Matemática pela Universidade Estadual de Campinas (UNICAMP). Professora do Ifes - Campus Nova Venécia.

\section{Sandra Menezes}

Mestra em Modelagem Computacional pela Universidade Estadual do Rio de Janeiro (UERJ). Doutoranda em Ensino de Ciências e Matemática pela Universidade Estadual de Campinas (UNICAMP).

\section{Glauce Barbosa Verão}

Doutora em Matemática pela Universidade de São Paulo (USP). Docente na Universidade Virtual do Estado de São Paulo (Univesp) e na Universidade São Judas

Artigo recebido em: 23/11/2020

Aceito para publicação em :08/01/2021

Para citar este trabalho:

COTRIM, Fabiana Santos;LIMA, Lilian Patrícia; CEZAR, Mariana dos Santos; MENEZES, Sandra; VERÃO, Glauce Barbosa. FATORES DE ENGAJAMENTO DOS LICENCIANDOS EM PEDAGOGIA NA PARTICIPAÇÃO DE LIVES EM UM CURSO A DISTÂNCIA. Revista Paidéi@. Unimes Virtual. Volume 13- Número 23 . Janeiro-2021. Disponível em:

https://periodicos.unimesvirtual.com.br/index.php/paideia/index 